\title{
Strategic Interactions between an Independent Central Bank and a Myopic Government with Government Debt
}

Sven Jari Stehn and David Vines

INTERNATIONAL MONETARY FUND 



\title{
IMF Working Paper
}

Fiscal Affairs Department

\section{Strategic Interactions between an Independent Central Bank and a Myopic Government with Government Debt}

\author{
Prepared by Sven Jari Stehn and David Vines*
}

Authorized for distribution by Steven Symansky

July 2008

\begin{abstract}
This Working Paper should not be reported as representing the views of the IMF. The views expressed in this Working Paper are those of the author(s) and do not necessarily represent those of the IMF or IMF policy. Working Papers describe research in progress by the author(s) and are published to elicit comments and to further debate.
\end{abstract}

We analyse optimal discretionary games between a benevolent central bank and a myopic government in a New Keynesian model. First, when lump-sum taxes are available and public debt is absent, we show that a Nash game results in too much government spending and excessively high interest rates, while fiscal leadership reinstates the cooperative outcome under discretion. Second, we show that this familiar result breaks down when lump-sum taxes are unavailable. With government debt, the Nash equilibrium still entails too much public spending but leads to lower interest rates than the cooperative policy, because debt has to be adjusted back to its pre-shock level to ensure time consistency. A setup of fiscal leadership does not avoid this socially costly outcome. Imposing a debt penalty onto the myopic government under either Nash or fiscal leadership raises welfare substantially, while appointing a conservative central bank is less effective.

JEL Classification Numbers:E52, E60, E61, E63

Keywords: Monetary and Fiscal Policy, Policy Myopia, Non-cooperative games, Stabilisation Bias

Author's E-Mail Address:sstehn@,imf.org, david.vines@economics.ox.ac.uk

\footnotetext{
* We would like to thank Charles Bean, Mark de Broeck, Xavier Debrun, Daniel Leigh, Steven Symansky, Tanya Kirsanova, Campbell Leith, Warwick McKibbin, John Muellbauer, Michael Woodford and Simon Wren-Lewis, and participants at seminars at Oxford University, the Australian National University, the Reserve Bank of Australia and the Bank of England.
} 


\section{Contents}

I. Introduction . . . . . . . . . . . . . . . . . . . . . 4

II. The Model . . . . . . . . . . . . . . . . . . . . . . . . . . . 6

A. Consumers . . . . . . . . . . . . . . . . 6

B. Price Setting . . . . . . . . . . . . . . . . . 7

C. Aggregate Demand and Fiscal Policy . . . . . . . . . . . . 8

D. The System . . . . . . . . . . . . . . . . . . . . . . . . . . . . . . . . . . . 9

E. Social Welfare . . . . . . . . . . . . . . . . . . . . . 9

F. Policy Objectives . . . . . . . . . . . . . . . . . . 10

G. Calibration ........................... 11

III. Solving for Optimal Policy . . . . . . . . . . . . . . . . . . . . . . . . . . . . . 11

A. Cooperative Policy . . . . . . . . . . . . . . . . . 11

B. Non-Cooperative Policy under Discretion . . . . . . . . . . . . . 11

IV. Optimal Policy when Lump-Sum Taxes are Available . . . . . . . . . . . . . 13

A. Cooperative Policy . . . . . . . . . . . . . . . . 13

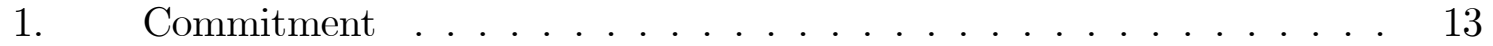

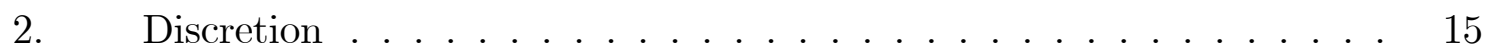

B. Non-Cooperative Policy with a Myopic Fiscal Authority . . . . . . . . 15

1. Nash . . . . . . . . . . . . . . . . . 17

2. Fiscal Leadership . . . . . . . . . . . . . . . . . . . 18

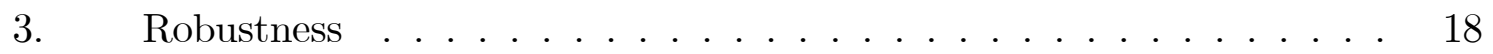

V. Optimal Policy when Lump-Sum Taxes are not Available . . . . . . . . . . . . . . 20

A. Cooperative Policy . . . . . . . . . . . . . . . . . 20

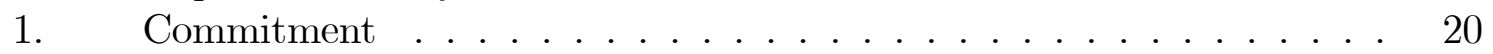

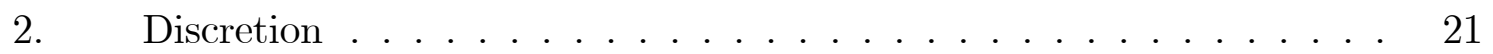

B. Non-Cooperative Policy with a Myopic Fiscal Authority . . . . . . . . 22

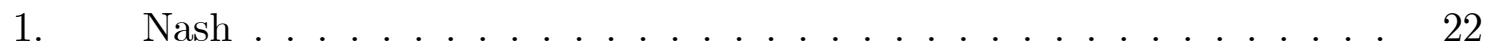

2. Fiscal Leadership . . . . . . . . . . . . . . . . . . . . . . . . . . . . . . . . . . . . .

C. Robustness . . . . . . . . . . . . . . . . . 23

VI. Optimal Institutions _. . . . . . . . . . . . . . . . . . . . . . . 24

A. A Debt Penalty . . . . . . . . . . . . . . . . 25

B. A Conservative Central Bank . . . . . . . . . . . . . . . . 27

VIIConclusion . . . . . . . . . . . . . . . . . . . . . . . . 29

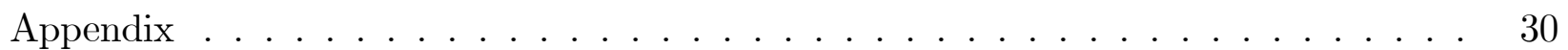

A. Social Welfare ....................... 30

B. Policy Myopia . . . . . . . . . . . . . . . . . . . 31

C. Solving the Model . . . . . . . . . . . . . . . . . . 31

1. Optimal Cooperative Policy . . . . . . . . . . . . . 32 
2. Optimal Non-Cooperative Policy under Discretion . . . . . . . . . . 33

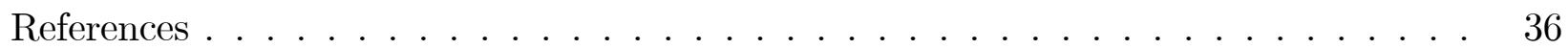

Tables

Table 1. Optimal policy simulations for a transitory cost-push shock. . . . . . . . 12

Figures

Figure 1. Dynamic responses to a transitory cost-push shock under optimal policy. . 14

Figure 2. First-period responses to a transitory cost-push shock under optimal policy for different degrees of fiscal myopia $(p) . \quad \ldots \ldots \ldots \ldots \ldots$

Figure 3. First-period responses to a transitory cost-push shock under optimal policy with a myopic government $(p=0.75)$ for different calibrations. $\ldots \ldots$.

Figure 4. Optimal policy without lump-sum taxes with a myopic government ( $p=$ $0.75)$ and a debt penalty. . . . . . . . . . . . . 26

Figure 5. Optimal policy without lump-sum taxes and a myopic government ( $p=$ $0.75)$ for different degrees of monetary conservatism $(\eta)$. . . . . . . 


\section{Introduction}

Many countries have adopted a macro-economic framework in which monetary policy is conducted by an independent central bank and fiscal policy is set by the government. Within this setup, the conventional assignment is for monetary policy to perform the bulk of the stabilisation of shocks, while the government ensures the sustainability of public debt. The delegation of monetary policy to an independent central bank is a powerful tool to shield its stabilisation role from the incentives elected governments face, including the temptation of boosting output above potential or adopting a short-term outlook. Fiscal policy, however, remains subject to these incentives. Given that this widely-adopted framework deliberately assigns different objectives to the two policymakers, it is of particular interest to analyse how the outcome of their strategic interaction differs from the conventional assignment.

The traditional literature has studied this question in one-period games. ${ }^{1} \mathrm{~A}$ recent and influential paper in this spirit is that by Dixit and Lambertini (2003: henceforth DL). They show that if the fiscal and monetary policymakers have different objectives, a Nash game can result in a 'fight' in the conduct of policy. Allowing the fiscal policymaker to act as the Stackelberg leader, generally produces less extreme outcomes. The key shortcoming of DL is that they consider a static game. This literature can therefore neither analyse the role of public debt in the policy interaction, nor the disagreement about inter-temporal policy trade-offs. We consider both of these aspects to be critical in understanding the interactions between monetary and fiscal policy.

Beetsma and Bovenberg (1997b: henceforth BB) provide an analysis of these inter-temporal issues in a dynamic game using a two-period model. The inclusion of public debt adds an additional source of time inconsistency to optimal policy. To counter the incentive to create surprise inflation to dis-inflate the stock of debt, less debt is accumulated in the first period under discretion than under commitment. When a myopic government plays a Nash game with the central bank under discretion, BB show that the government accumulates more debt in the first period than a benevolent policymaker under discretion in order to encourage the central bank to create more inflation in the second period. Imposing a debt target onto the myopic government in these circumstances raises welfare, but does not reproduce the commitment outcome unless the central bank is made appropriately conservative.

Kirsanova, Stehn and Vines (2005: henceforth KSV) study dynamic games in a simple infinite-horizon model. KSV show that, when a myopic government and a benevolent central bank play a Nash game in response to a cost-push shock, a fight similar to that in DL develops. The central bank attempts to reduce inflation quickly, by raising the interest rate, but the short-sighted government wants to postpone the resulting recession, and increases public spending. Higher government spending, in turn, causes the central bank to raise the interest rate more until a Nash equilibrium with excessively high interest rates,

\footnotetext{
${ }^{1}$ See, for example, Alesina and Tabellini (1987), Beetsma and Bovenberg (1997a), Castellani and Debrun (2005) and Lambertini (2006).
} 
too much spending, and a large increase in government debt is found. ${ }^{2}$ By contrast, and similar to the mechanism in DL, if the myopic government is a Stackelberg leader, then it will not attempt to spend excessively so as to offset the monetary contraction, because it anticipates that the effects of such action will be undone by the central bank. For computational simplicity of the dynamic games, KSV use a non-microfounded model which is backward-looking. This simple model has two important shortcomings. Firstly, it lacks forward-looking expectations which prevent KSV from studying issues of time consistency. Secondly, one cannot construct a micro-founded metric of social welfare for this model.

The present paper overcomes these two shortcomings and analyses the robustness of the conclusions of DL, BB and KSV by studying optimal dynamic games in an infinite-horizon New Keynesian model with government debt. Our work builds on two strands of the recent literature. First, there are a number of papers which characterise the optimal cooperative policy for monetary and fiscal policy in New Keynesian models with government debt. Benigno and Woodford (2003) and Schmitt-Grohe and Uribe (2004) show that optimal commitment policy implies a random walk in public debt. Leith and Wren-Lewis (2007), however, show that such policy is time inconsistent and that debt under optimal discretionary policy has to be returned to its pre-shock level to ensure time consistency. Stehn and Vines (2008) show in detail how this 'debt stabilisation bias' constrains monetary policy in its response to cost-push shocks, as monetary policy contributes to the required debt adjustment with lower interest rates, and necessitates more active fiscal policy than under commitment. Second, Blake and Kirsanova (2006) have recently developed an algorithm for solving dynamic games under discretion in rational expectations models. ${ }^{3}$

Using these two strands of the literature, we analyse the strategic interactions between a benevolent central bank and a myopic government in response to cost-push shocks. First, when lump-sum taxes are available and public debt is absent, we show that a Nash game results in too much government spending and excessively high interest rates, while fiscal leadership reinstates the cooperative outcome under discretion. Second, we show that this result - which is familiar from DL and KSV - breaks down when lump-sum taxes are unavailable. With government debt, the Nash equilibrium still entails too much public spending but leads to lower interest rates than the cooperative policy under discretion. This is because debt has to be returned to its pre-shock level under discretionary policy, and with the myopic government contributing insufficiently to the required adjustment, monetary policy takes on the additional reduction of debt. ${ }^{4}$ A setup of fiscal leadership does not avoid this socially costly outcome. Imposing a debt penalty onto the myopic government under either Nash or fiscal leadership raises welfare substantially, while appointing a conservative central bank is less effective.

\footnotetext{
${ }^{2}$ In KSV monetary and fiscal policy are perfect substitutes in their effect on output and inflation which means that in this fight the dynamics of output and inflation are unchanged. The costs of the fight therefore stem from the excessive volatility of government spending.

${ }^{3}$ We would like to thank Tanya Kirsanova for providing us with the Matlab code to implement this algorithm.

${ }^{4}$ Given the microfounded structure of our model we assume - unlike BB - that the central bank does not ignore the accumulation of government debt but internalises all constraints when maximising social welfare.
} 
The remainder of the paper is structured as follows. Section II. introduces the model and section III. outlines the solution method. Section IV. analyses optimal policy when lump-sum taxes are available, and section V. studies optimal policy with government debt accumulation. Section VI. explores optimal institutions and section VII. concludes.

\section{The Model}

The model is an extended version of the standard New Keynesian model of Woodford (2003a) and includes fiscal policy. The model we use in this paper is based on Kirsanova and Wren-Lewis (2007). ${ }^{5}$

\section{A. Consumers}

The economy is populated by a continuum of infinitely lived individuals, who specialise in the production of a differentiated good (indexed by $z$ ), and who spend $H(z)$ of effort in its production. They consume a basket of goods $C$, and derive utility from per capita government consumption $G$. The individual's maximisation problem is:

$$
\max _{\left\{C_{s}, h_{s}\right\}_{s=t}^{\infty}} E_{t} \sum_{s=t}^{\infty} \beta^{s-t}\left[u\left(C_{s}\right)+f\left(G_{s}\right)-v\left(H_{s}(z)\right)\right]
$$

The price of the differentiated good $z$ is given by $p(z)$ and the corresponding aggregate price level is given by $P$. Each individual chooses his optimal consumption and work effort to maximise his utility function (1) subject to the demand system and the intertemporal budget constraint:

$$
P_{t} C_{t}+E_{t} R_{t, t+1} \bar{A}_{t+1} \leq \bar{A}_{t}+(1-\tau)\left(W_{t}(z) H_{t}(z)+\Omega_{t}(z)\right)+T
$$

where $P_{t} C_{t}=\int_{0}^{1} p(z) c(z) d z$ is nominal consumption, $\bar{A}_{t}$ are nominal financial assets of a household, $\Omega_{t}$ is profit and $T$ is a steady-state lump-sum tax. The nominal wage rate is given by $W_{t}$ and $\tau$ is an exogenous labour income tax rate. $R_{t, t+1}$ is the stochastic discount factor which denotes the price in period $t$ of carrying the state-contingent asset $\bar{A}_{t+1}$ into period $t+1$. We can express the stochastic discount factor in terms of the riskless one period nominal interest rate $i_{t}$ :

$$
E_{t}\left(R_{t, t+1}\right)=\frac{1}{1+i_{t}}
$$

\footnotetext{
${ }^{5}$ The models of Benigno and Woodford (2003) and Leith and Wren-Lewis (2007) are similar to this setup but differ to the extent that they treat distortionary taxes as a fiscal instrument which enters the Phillips curve and therefore allow for direct stabilisation of cost-push shocks. Whilst either taxes or government spending can be taken as the fiscal instrument to study the problem of this paper, we choose government spending which affects inflation only through its effect on aggregate demand.
} 
Individuals consume identical baskets of goods which are aggregated into a Dixit and Stiglitz (1977) consumption index. The elasticity of substitution between any pair of goods is assumed to be stochastic to allow for shocks to the mark-up of firms and is given by $\varepsilon_{t}>1$ with mean $\varepsilon$. The consumption index is given by $C_{t}=\left[\int_{0}^{1} c_{t}^{\frac{\varepsilon_{t}-1}{\varepsilon_{t}}}(z) d z\right]^{\frac{\varepsilon_{t}}{\varepsilon_{t}-1}}$.

We assume no Ponzi schemes, that the net present value of individual's income and wealth is bounded ${ }^{6}$ and that the nominal interest rate is always positive. By ruling out infinite consumption, this allows us to summarise the infinite sequence of budget constraints as a single intertemporal constraint:

$$
E_{t} \sum_{s=t}^{\infty} R_{t, s} C_{s} P_{s} \leq \bar{A}_{t}+E_{t} \sum_{s=t}^{\infty} R_{t, s}\left[(1-\tau)\left(W_{s}(z) H_{s}(z)+\Omega_{s}(z)\right)+T\right]
$$

Household optimisation determines the following dynamic evolution of consumption:

$$
\beta E_{t}\left(\left(\frac{C_{t+1}}{C_{t}}\right)^{-\frac{1}{\sigma}} \frac{P_{t}}{P_{t+1}}\right)=\frac{1}{1+i_{t}}
$$

where the intertemporal elasticity of substitution is defined as $\sigma=-u_{C} / u_{C C} C=-f_{G} / f_{G G} G$. Aggregate nominal assets accumulate according to:

$$
\bar{A}_{t+1}=\left(1+i_{t}\right)\left(\bar{A}_{t}+(1-\tau) P_{t} Y_{t}-P_{t} C_{t}-T\right)
$$

For each variable $X_{t}$ we denote its steady-state value as $X$ and its logarithmic deviation from this steady state as $\hat{X}_{t}=\ln \left(X_{t} / X\right)$. Linearising equation (2) leads to a standard Euler equation:

$$
\hat{C}_{t}=E_{t} \hat{C}_{t+1}-\sigma\left(\hat{\imath}_{t}-E_{t} \pi_{t+1}\right)
$$

where we defined the inflation rate as $\pi_{t}=P_{t} / P_{t-1}-1$ and assume steady-state inflation is zero.

\section{B. Price Setting}

Price setting is based on Calvo contracting in which firms re-calculate their prices with fixed probability $(1-\gamma)$. If prices are not re-calculated, they remain fixed. Following Woodford (2003a) we derive the following Phillips curve:

$$
\hat{\pi}_{t}=\beta E_{t} \hat{\pi}_{t+1}+\kappa \hat{S}_{t}
$$

\footnotetext{
${ }^{6}$ The requirement that the household's wealth accumulation satisfies the transversality condition is given by $\lim _{s \rightarrow \infty} E_{t}\left(R_{t, s} \bar{A}_{s}\right)=0$.
} 
with

$$
\kappa=\frac{(1-\gamma \beta)(1-\gamma) \psi}{\gamma(\psi+\varepsilon)}
$$

To determine real marginal cost $\left(\hat{S}_{t}\right)$ we assume that the production function for good $z$ is given by $Y_{t}(z)=H_{t}(z)$ and that the cost of supplying a good is given by $W_{t}(z) H_{t}(z)$. Real marginal cost is then given by:

$$
\hat{S}_{t}=\frac{1}{\psi} \hat{Y}_{t}+\frac{1}{\sigma} \hat{C}_{t}+\hat{\mu}_{t}
$$

where we defined $\psi=v_{y} / v_{y y} Y$ and $\hat{\mu}_{t}$ is a 'cost-push' shock (see Clarida et al 1999).

\section{Aggregate Demand and Fiscal Policy}

Aggregate demand is given by the national income identity:

$$
Y_{t}=C_{t}+G_{t}
$$

In steady state we assume $G=(1-\theta) Y$ where $\theta$ is the share of private consumption in output. Linearising the income identity:

$$
\hat{Y}_{t}=\theta \hat{C}_{t}+(1-\theta) \hat{G}_{t}
$$

where $\theta=C / Y$ is the steady-state share of private consumption in output ${ }^{7}$

The government buys goods, taxes income with a constant income tax rate $\tau$ and issues one-period, non-indexed debt $\bar{B}$. The evolution of nominal (non-indexed) debt is given by:

$$
\bar{B}_{t+1}=\left(1+i_{t}\right)\left(\bar{B}_{t}+P_{t} G_{t}-\tau P_{t} Y_{t}-T\right)
$$

Linearising the debt evolution equation:

$$
\hat{B}_{t+1}=\hat{\imath}_{t}+\frac{1}{\beta}\left(\hat{B}_{t}-\hat{\pi}_{t}+\frac{(1-\theta)}{B} \hat{G}_{t}-\frac{\tau}{B} \hat{Y}_{t}\right)
$$

where we defined the real debt stock as $B_{t}=\bar{B}_{t} / P_{t-1}$ and $B$ as the steady-state ratio of debt to output. ${ }^{8}$ Public debt at the beginning of period $t+1$ depends on existing debt, real interest payments, government spending and tax revenues through the constant income tax rate.

\footnotetext{
${ }^{7} \mathrm{~A}$ model-consistent value of $\theta$ can be derived from the utility function in steady state, see Kirsanova and Wren-Lewis (2007).

${ }^{8}$ With lump-sum taxes, any debt stock in steady state can be matched by the appropriate level such taxes. We therefore take this debt ratio as given and discuss its calibration in Section G.. The choice of $B$ in turn determines the steady-state tax rate $\tau$.
} 


\section{The System}

We obtain a system of equations that describes the evolution of the out-of-equilibrium economy. We follow convention in denoting lower case letters to denote 'gap' variables, where the gap is the difference between actual and flexible-price (or 'natural') levels $\left(x_{t}=\hat{X}_{t}-\hat{X}_{t}^{n}\right)$. As government debt is the only asset in the economy we have $\hat{A}_{t}=\hat{B}_{t}$. We obtain the following system:

$$
\begin{gathered}
c_{t}=E_{t} c_{t+1}-\sigma\left(i_{t}-E_{t} \pi_{t+1}\right) \\
\pi_{t}=\beta E_{t} \pi_{t+1}+\kappa\left(\frac{1}{\sigma} c_{t}+\frac{1}{\psi} y_{t}\right)+\mu_{t} \\
y_{t}=(1-\theta) g_{t}+\theta c_{t} \\
b_{t+1}=i_{t}+\frac{1}{\beta}\left(b_{t}-\pi_{t}+\frac{(1-\theta)}{B} g_{t}-\frac{\tau}{B} y_{t}\right)
\end{gathered}
$$

The complete model consists of a standard intertemporal Euler equation (10), a New

Keynesian Phillips curve (11), a linearised aggregate demand relationship (12) and an equation for the evolution of government debt (12).

\section{E. Social Welfare}

Next we follow Woodford (2003a) and Kirsanova and Wren-Lewis (2007) in using a second-order approximation of the aggregate utility function to show that the model-consistent social welfare function can be expressed as (see Appendix A.):

$$
\frac{1}{2} E_{t} \sum_{s=t}^{\infty} \beta^{s-t}\left[u\left(C_{s}\right)+f\left(G_{s}\right)-\int_{0}^{1} v\left(H_{s}(z)\right) d z\right]=-\frac{1}{2} E_{t} \sum_{s=t}^{\infty} \beta^{s-t} W_{s}
$$

where the period loss function $W_{s}$ given by:

$$
W_{s}=\lambda_{\pi} \pi_{s}^{2}+\lambda_{c} c_{s}^{2}+\lambda_{y} y_{s}^{2}+\lambda_{g} g_{s}^{2}
$$

where we ignore terms of higher than second order and terms independent of policy. The coefficients are defined as:

$$
\lambda_{\pi}=\frac{(\varepsilon+\psi) \gamma \varepsilon}{\psi(1-\gamma \beta)(1-\gamma)}, \lambda_{c}=\frac{\theta}{\sigma}, \lambda_{y}=\frac{1}{\psi}, \lambda_{g}=\frac{(1-\theta)}{\sigma}
$$

Social welfare consists of two sets of terms. Firstly, quadratic terms in $c, g$ and $y$ arise because the representative consumer attempts to smooth both private and public consumption and dislikes fluctuations in hours worked. Secondly, in a model with Calvo pricing, inflation induces price dispersion across industries, which carries a quadratic cost (Woodford 2003a). As this relationship between price dispersion and inflation is inter-temporal, the relative weight attached to inflation $\left(\lambda_{\pi}\right)$ depends on the discount rate of the representative agent $(\beta)$, see Appendix A.. 


\section{F. Policy Objectives}

In this paper we assume that the delegation of monetary policy to an independent central bank in itself eliminates the distortion in the monetary policy objectives, while the government retains the original incentives (consistent with McCallum 1995). Unlike DL and $\mathrm{BB}$, who assume that policymakers target an output level above potential, we will model the distortion in the government's objectives as policy myopia. ${ }^{9}$ This short-term bias is motivated by elections. ${ }^{10}$

The benevolent central bank is therefore assumed to maximises social welfare $\left(W_{s}^{M}=W_{s}\right)$ subject to the evolution of the economy, (10)-(12). Notice that BB, in contrast, assume that the independent central bank ignores the evolution of government debt. Given the micro-founded nature of our model - in which government debt simultaneously acts as the stock of assets of the representative agent - it is natural to assume that the independent central bank takes into account all constraints when maximising social welfare. While the government maximises the same period utility function as the representative agent, it is assumed to discount the future more heavily because it faces an exogenous probability, $(1-p) \geq 0$, of being voted out of office in the following period. The government's effective discount rate is therefore given by $p \beta$. A second-order approximation to the myopic government's utility maximisation problem is given by (see Appendix B.):

$$
E_{t} \frac{1}{2} \sum_{s=t}^{\infty}(p \beta)^{s-t} W_{s}^{F}
$$

with

$$
W_{s}^{F}=\lambda_{\pi}^{F} \pi_{s}^{2}+\lambda_{c} c_{s}^{2}+\lambda_{y} y_{s}^{2}+\lambda_{g} g_{s}^{2}
$$

where we again ignore terms of higher than second order and terms independent of policy, and:

$$
\lambda_{\pi}^{F}=\frac{(\varepsilon+\psi) \gamma \varepsilon}{\psi(1-\gamma p \beta)(1-\gamma)}
$$

We see that myopia affects the preferences for both the inter-temporal and the intra-temporal allocation of losses. First, the inter-temporal effect of myopia is obvious from (16): the government attaches a lower weight to future period-by-period losses than the social welfare function. Second, myopia has an intra-temporal effect as the myopic government attaches less weight to inflation terms relative to other terms compared to the social welfare function (for $p<1$ we have $\lambda_{\pi}^{F}<\lambda_{\pi}$ ). This is because the relationship between price dispersion and inflation is dynamic (see Appendix A.). If the government discounts excessively, its cares too little about the effect of current inflation on future price

\footnotetext{
${ }^{9}$ We follow Woodford (2003a) in abstracting from the level bias problem by allowing a steady-state subsidy to offset the effects of imperfect competition on output (see Appendix A.).

${ }^{10}$ Cukierman et al (1992) show how political instability affects the effective rate of time preference. Although rational voters should not re-elect short-sighted policymakers, imperfect information can render policy myopia constrained efficient (Rogoff 1990).
} 
dispersion - which is equivalent to caring less about inflation relative to other terms in welfare.

\section{G. Calibration}

We follow the recent literature in assuming a time period to be a quarter and set $\beta=0.99$, $\sigma=0.5, \psi=2, \varepsilon=7$ and $\gamma=0.75$ (e.g. Woodford 2003a). The Calvo parameter $\gamma$ implies that prices are on average set once a year. Following Kirsanova and Wren-Lewis (2007), we set the steady-state share of private consumption in output to $\theta=0.75$ and the steady-state ratio of debt to output to $B=0.1$. Our simulations consider an i.i.d. cost-push shock with a standard deviation of 0.005 . The baseline scenario sets $p=0.75$. A robustness section will consider the sensitivity of our results to these calibrations.

\section{Solving for Optimal Policy}

This section outlines the solution method and delegates details to Appendix C..

\section{A. Cooperative Policy}

Under cooperative (or 'centralised') policy, a single policymaker chooses both the interest rate and government spending to minimise the social loss function subject to the evolution of the economy. ${ }^{11}$ Under optimal commitment policy, the policymaker is able to manipulate private sector expectations by committing to any (including time-inconsistent) policy plans (Currie and Levine 1993). Given the linear quadratic nature of this problem, optimal policy may be expressed as a linear instrument rule that responds to the predetermined variables in the system (see Appendix 1.). Optimal policy under discretion, in contrast, have to be time consistent (Currie and Levine 1993). ${ }^{12}$ The reaction functions for the interest rate and spending under optimal discretionary policy each respond to the cost-push shock and, if lump-sum taxes are unavailable, also the existing debt stock (see Appendix 1.). Our simulations will summarise optimal policies under discretion by reporting the value of these feedback coefficients.

\section{B. Non-Cooperative Policy under Discretion}

In our analysis of non-cooperative (or 'decentralised') policy, the government and the central bank minimise their individual loss functions by choosing government spending and

\footnotetext{
${ }^{11}$ This setup can be interpreted either as a dependent central bank or as cooperation between a government and a central bank who share the same objectives.

${ }^{12}$ Time consistency requires the Lagrange mutlipliers associated with the non-predetermined variables to be zero.
} 
the interest rate respectively, subject to the evolution of the economy. We will analyse games played under discretion because we believe this interaction to be the most relevant for policy in practice. To solve for non-cooperative games, we will use the solution approach of Blake and Kirsanova (2006), which is described in detail in Appendix 2.. Firstly, we will solve for the Nash outcome in which the central bank and the government set their instruments simultaneously, and treat each other's actions parametrically. The optimal feedback rules can be expressed in terms of responses to the shock and, without lump-sum taxes, the debt stock (see Appendix 2.). Secondly, we will consider a regime of fiscal leadership in which the government can move first as the Stackelberg leader in its interaction with the central bank. In a fiscal leadership regime, the government takes into account the reaction function of the central bank when setting its own policy. The government's reaction function for government spending includes the cost-push shock and existing debt, just as under Nash and the cooperative policy (see Appendix 2.). The interest rate reaction function of the central bank also includes a response to government spending. When reporting the results, we will again express the interest rate feedback rule as a function of the cost-push shock and, in the case without lump-sum taxes, also debt.

Table 1: Optimal policy simulations for a transitory cost-push shock. D denotes cooperation under discretion. $\mathrm{N}$ and FL denote policy with a myopic government $(p=0.75)$ under Nash and fiscal leadership respectively.

\begin{tabular}{|c|c|c|c|c|c|c|}
\hline & \multicolumn{3}{|c|}{ Lump-Sum Taxes } & \multicolumn{3}{|c|}{ No Lump-Sum Taxes } \\
\hline & $\mathrm{D}$ & $\mathrm{N}$ & FL & $\mathrm{D}$ & $\mathrm{N}$ & FL \\
\hline & $(1)$ & $(2)$ & $(3)$ & $(4)$ & $(5)$ & (6) \\
\hline \multicolumn{7}{|c|}{ Welfare Loss } \\
\hline Loss & 0.4256 & 0.4258 & 0.4256 & 0.4917 & 0.5056 & 0.5049 \\
\hline$\% \mathrm{C}$ & - & 0.0002 & 0.0000 & - & 0.0139 & 0.0132 \\
\hline \multicolumn{7}{|c|}{ Optimal Monetary Feedback Rule $\left(i_{t}=\theta_{\mu} \mu_{t}+\theta_{b} b_{t}\right)$} \\
\hline Shock $\left(\theta_{\mu}\right)$ & 13.12 & 13.17 & 13.12 & 8.88 & 5.84 & 5.74 \\
\hline $\operatorname{Debt}\left(\theta_{b}\right)$ & - & - & - & -0.01 & -0.03 & -0.03 \\
\hline \multicolumn{7}{|c|}{ Optimal Fiscal Feedback Rule $\left(g_{t}=\phi_{\mu} \mu_{t}+\phi_{b} b_{t}\right)$} \\
\hline $\operatorname{Shock}\left(\phi_{\mu}\right)$ & 0.00 & 0.49 & 0.00 & -5.50 & -4.61 & -4.72 \\
\hline Debt $\left(\phi_{b}\right)$ & - & - & - & -0.11 & -0.11 & -0.11 \\
\hline
\end{tabular}




\section{Optimal Policy when Lump-Sum Taxes are Available}

We start by considering optimal policy in an economy in which lump-sum taxes are available. That is, we follow DL in assuming that the policymaker can freely choose the level of lump-sum taxes necessary to fulfil the intertemporal budget constraint, making the accumulation of debt unnecessary. ${ }^{13}$ We first set out the cooperative benchmark (section A.) before turning to non-cooperative games with a myopic government (section B.).

We solve for optimal policy in response to a cost-push shock and present the dynamic responses for our baseline calibration in Figure $1 .{ }^{14}$ The left hand column plots the impulse responses when lump-sum taxes are available. We report the dynamics for cooperative policy under commitment and discretion, as well as optimal discretionary policy for a myopic government under Nash and fiscal leadership. Columns (1) to (3) in Table 1 report further simulation details. The first part presents the absolute welfare losses ('Loss') and the excess losses over the cooperative discretionary solution (expressed in terms of percentage of steady-state consumption foregone, $\% C$ ). The bottom part of the table presents the coefficients of the optimal reaction functions for the three discretionary regimes. Figure 2 summarises optimal policy outcomes for different degrees of fiscal myopia. The top five rows present the first-period responses of the system to the cost-push shock $^{15}$ and the bottom row reports the corresponding excess welfare loss over the cooperative policy under discretion.

\section{A. Cooperative Policy}

We begin by outlining the cooperative benchmark in which a single policymaker optimises under commitment (section 1.) and discretion (section 2.).

\section{Commitment}

Figure 1 shows that the policymaker under commitment (solid line with crosses) raises the nominal interest rate persistently in response to the rise in inflation. The resulting increase in the real interest rate induces a fall in consumption which reduces real marginal cost and therefore inflation. Optimal commitment policy is highly effective in achieving this

\footnotetext{
${ }^{13}$ Formally, we allow $T$ in (8) to vary over time.

${ }^{14}$ We use the algorithm of Soderlind (1999) to simulate the dynamic response of the system to a cost-push shock under optimal cooperative policy and the algorithm of Blake and Kirsanova (2006) to solve for optimal policy under fiscal leadership and Nash. We would like to thank Tanya Kirsanova for allowing us to use her solution code.

${ }^{15}$ With a unit cost-push shock, the first-period interest rate and public spending movements are identical to their feedback coefficients onto the cost-push shock. For the baseline degree of fiscal myopia $(p=0.75)$, the feedback coefficients reported in Table 1 are hence identical to the first period policy responses in Figure 2 .
} 
Figure 1: Dynamic responses to a transitory cost-push shock under optimal policy.
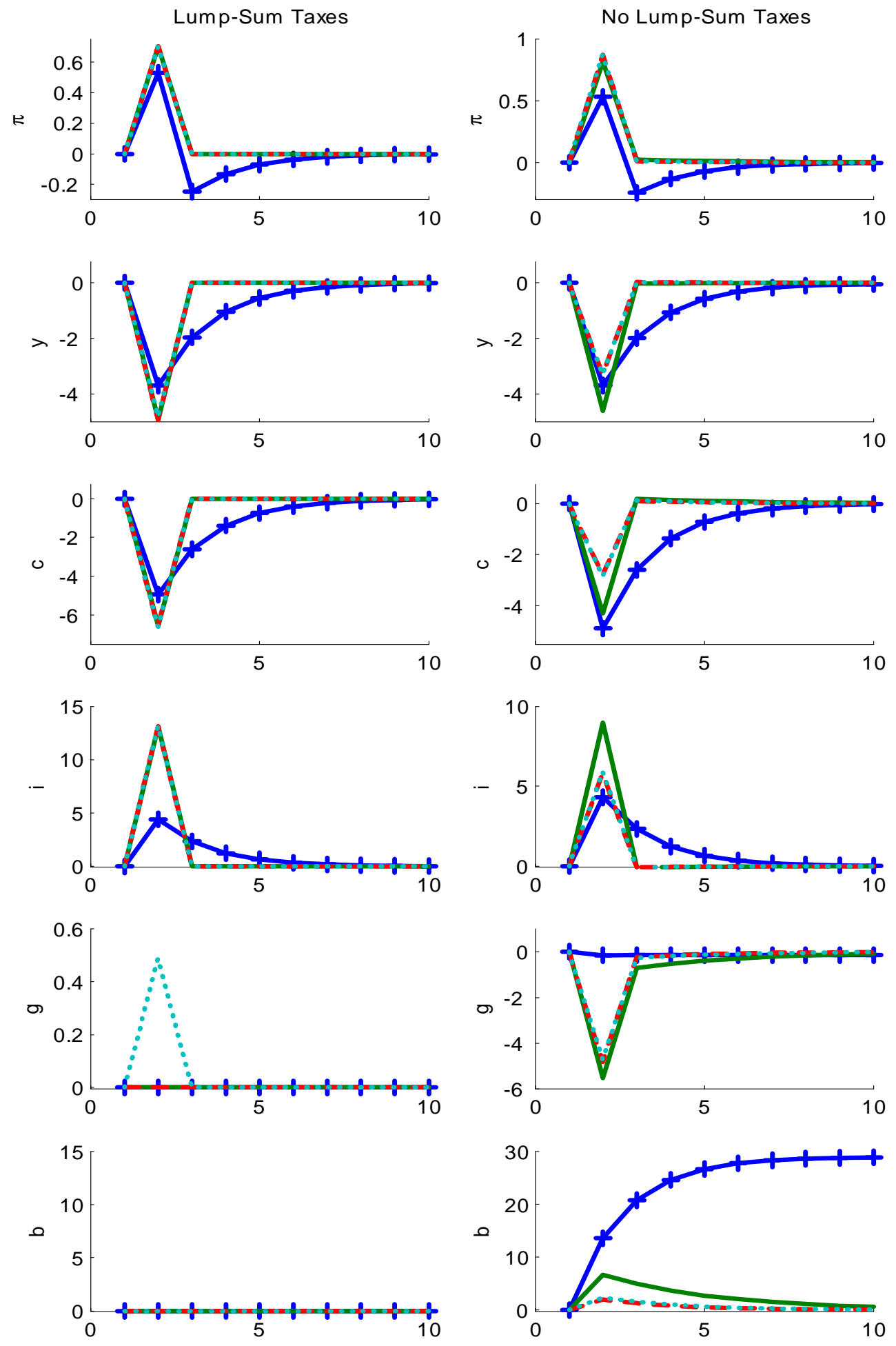

$\longrightarrow$ Cooperation (Commitment) Cooperation (Discretion)

$$
\text { - - Fiscal leadership ...... Nash }
$$


disinflation by committing to and delivering contractionary policy in the future. This is achieved through a gradual response to the cost-push shock in which the interest rate is slowly smoothed back to zero.

We see that optimal fiscal policy is inactive in response to the cost-push shock (see also Kirsanova and Wren-Lewis 2007 and Stehn and Vines 2008). The policymaker leaves the stabilisation of the cost-push shock entirely to monetary policy, for two reasons. Firstly, monetary policy is more effective in controlling real marginal cost - and hence inflation than fiscal policy. Unlike government spending, the interest rate has both a direct effect (through consumption) and an indirect effect (through aggregate demand) on the real wage, and hence real marginal cost, through the optimal consumption-leisure choice. ${ }^{16}$ Secondly, movements in the fiscal instrument, in contrast to the monetary instrument, are costly, because they induce a suboptimal quantity of public spending. The policymaker therefore relies exclusively on the relatively 'cheaper' instrument to stabilise the cost-push shock.

This optimal commitment policy is time inconsistent (Currie and Levine, 1993). The policymaker is able to reduce current-period inflation, without a large recession in the present, by committing to tight monetary policy in the future. This is time inconsistent, because once low inflation has been achieved, the policymaker will no longer find it optimal to maintain high interest rates and will be tempted to renege on his initial plan.

\section{Discretion}

Optimal policy under discretion, in contrast, has to be time consistent. Figure 1 shows that inflation is controlled much less effectively under discretion (solid line) than commitment (solid line with crosses). The inability to control inflation tightly by manipulating inflation expectations under discretion results in the classic 'inflation stabilisation bias' of Currie and Levine (1993) and Woodford (2003b). Unable to promise high interest rates in the future, the policymaker raises interest rates very strongly in the first period. This first-period hike in interest rates induces a large recession but then interest rates are much more quickly returned to zero than under commitment which leads to slower inflation control. Fiscal policy under discretion - just as under commitment - is inactive in response to the cost-push shock when lump-sum taxes are available.

\section{B. Non-Cooperative Policy with a Myopic Fiscal Authority}

Next we turn to optimal non-cooperative policy under discretion between a benevolent central bank and a myopic government with lump-sum taxes. The next two sections will in turn show how the outcome of this strategic interaction differs under Nash (section 1.) and fiscal leadership (section 2.).

\footnotetext{
${ }^{16}$ Substituting (7) into (5) we see that the period-by-period interest rate effect on real marginal cost equals $\left(\frac{1}{\sigma}+\frac{\theta}{\psi}\right)$, compared to the fiscal impact of $\frac{(1-\theta)}{\psi}$.
} 
Figure 2: First-period responses to a transitory cost-push shock and welfare losses under optimal policy for different degrees of fiscal myopia $(p)$.
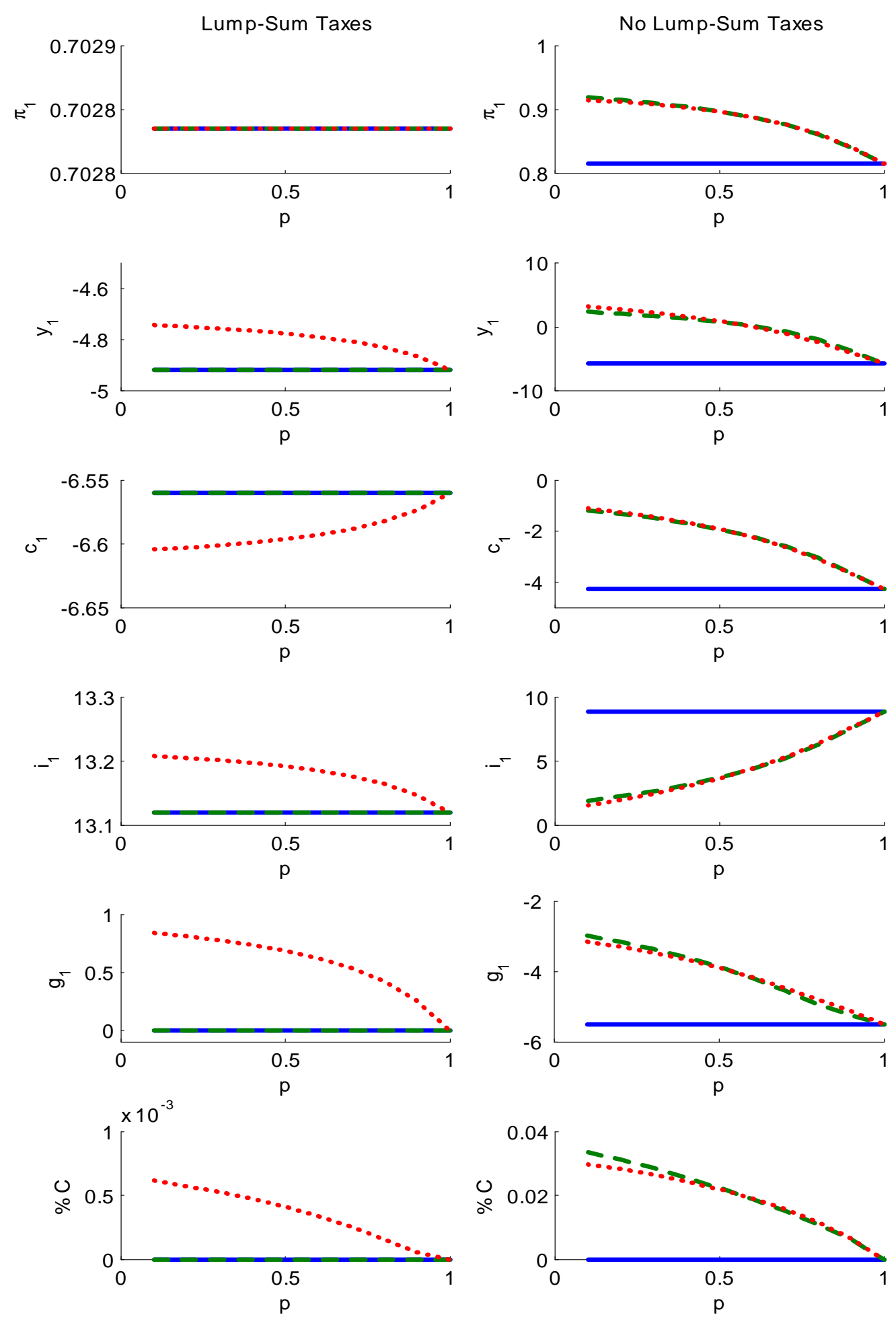


\section{Nash}

Figure 1 and Table 1 show that the myopic government under Nash (dotted line) is no longer inactive in its response to the cost-push shock but raises government spending in an attempt to dampen the effect of the monetary contraction. ${ }^{17}$ The central bank, in turn, raises interest rates by slightly more than the cooperative policy under discretion to achieve the desired disinflation. ${ }^{18}$ Monetary and fiscal policy therefore engage in a 'fight' over the desired path of disinflation, just as is familiar from DL and KSV. The central bank wants to reduce inflation quickly, by raising the interest rate strongly. But the myopic government wants to undo the recession which this contraction would cause, and therefore increases spending. This fiscal action, in turn, causes the central bank to raise the interest rate even more. As movements in the interest rate, in contrast to government spending, are costless the central bank tightens up to the point where the myopic government finds it too costly to expand even further. The resulting Nash outcome is one of higher interest rates and excessive public spending compared to the cooperative equilibrium under discretion.

We also note, however, that this fight is small in magnitude (indeed the monetary response is hardly visible in Figure 1). This is because monetary policy can easily offset the fiscal expansion as it is highly effective in controlling real marginal cost compared to fiscal policy. A slight increase in real interest rates contracts consumption sufficiently to offset the effect of higher spending on real marginal cost, and hence inflation (as monetary and fiscal policy are substitutes in their effect on inflation). ${ }^{19}$ Figure 2 highlights the mechanism of the fight by plotting the first-period responses of the system for different degrees of fiscal myopia $(p)$ alongside those of the cooperative discretionary policy. The left-hand column confirms that the myopic government under Nash raises spending on impact of the shock and shows that the central bank raises interest rates more than under cooperative discretionary policy in response. The increase in spending puts upward pressure on the output gap and hence real marginal cost relative to the cooperative response. The additional monetary tightening contracts consumption further up until the point at which the effect of higher output on real marginal cost, and therefore inflation, is undone. ${ }^{20}$ Figure 2 shows that the magnitude of this fight rises with the degree of fiscal myopia, while in the absence of conflicting objectives $(p=1)$, Nash leads to identical outcomes to those with cooperative policy under discretion. Therefore, the Nash outcome carries a small cost compared to the cooperative one due to higher consumption, output and government spending volatility (see Table 1), which rises with the degree of fiscal myopia (see the bottom row of Figure 2). However, as inflation variability, which carries by far the biggest weight in the micro-founded social loss function, is the same under Nash and cooperative policy, the magnitude of the excess loss is very small. ${ }^{21}$

\footnotetext{
${ }^{17}$ The fiscal response to the shock rises from zero to 0.49 , see column (2) in Table 1.

${ }^{18}$ The monetary response to the shock rises from 13.12 to 13.17 , see column (2) in Table 1.

${ }^{19} \mathrm{In} \mathrm{KSV}$ the perfect substitutability of the instruments in combination with the ad-hoc loss function (which penalised variations in output, but not consumption) generated a particularly severe instrument fight but left the dynamics of output and inflation exactly unchanged.

${ }^{20}$ That is, the monetary authority raises the interest rate until $\Delta c_{1}=-\frac{\sigma}{\psi} \Delta y_{1}$, where $\Delta$ denotes the difference between the cooperative equilibrium under discretion and the Nash outcome.

${ }^{21}$ The magnitude of the loss rises considerably for auto-correlated cost-push shocks. For example, a
} 


\section{Fiscal Leadership}

Figure 1 and Table 1 show that fiscal leadership (dashed line) is effective in avoiding this fight in that the myopic government does not spend excessively in response to the shock. ${ }^{22}$ The reason is familiar from DL and KSV: if the government is the Stackelberg leader, then, even if it is myopic, it will never be optimal for the government to spend excessively so as to attempt to delay the disinflation induced by monetary tightening. As the fiscal and monetary instruments are substitutes in their effect on real marginal cost, and hence inflation, it knows that the effect of extra spending on inflation will be undone by monetary tightening. As the leader, the myopic government internalises the monetary response with the resulting costs and chooses not to spend excessively. Figure 2 confirms that the instrument responses with fiscal leadership are identical to those with cooperative policy under discretion for all degrees of fiscal myopia. Fiscal leadership therefore leads to identical welfare outcomes to the cooperative policy under discretion (see Table 1) for all degrees of fiscal myopic (see the bottom row of Figure 2).

\section{Robustness}

Variations of the baseline calibration leave these findings unchanged. For brevity we will limit ourselves to a discussion of the interest rate and government spending responses (and leave aside a full assessment of the system and welfare implications). The left-hand of Figure 3 reports the first-period policy responses for two variations on the baseline calibration. Firstly, we show that the instrument fight intensifies in an economy with stronger price rigidities (higher $\gamma$ ). ${ }^{23}$ Stickier prices flatten the Phillips curve and raise the relative weight attached to inflation stabilisation in social welfare. The first two rows of Figure 3 show that this induces the myopic government to spend more excessively and the central bank hikes interest rates by more in response. Secondly, we see that changes to the relative effectiveness of monetary and fiscal policy affect the magnitude of the fight. An increase in the elasticity of substitution (higher $\sigma$ ) increases the responsiveness of consumption to the interest rate, but lowers the effect of consumption on real marginal cost (see equation (5)). ${ }^{24}$ This raises the effectiveness of public spending relative to consumption in controlling inflation. The third and fourth rows of Figure 3 show that the fight under Nash intensifies as the government raises spending more aggressively.

process with a first-order autoregressive parameter of 0.8 (as, for example, used in Woodford 2003a) leads to an increase in the excess loss of Nash by a factor of 15.

${ }^{22}$ The fiscal feedback coefficient on the shock remains at zero, see column (3) in Table 1.

${ }^{23}$ Raising the elasticity of substitution between goods $(\varepsilon)$ has similar effects.

${ }^{24}$ Lowering the elasticity of labour supply $(\psi)$ has similar effects. 
Figure 3: First-period responses to a transitory cost-push shock under optimal policy with a myopic government for alternative calibrations.
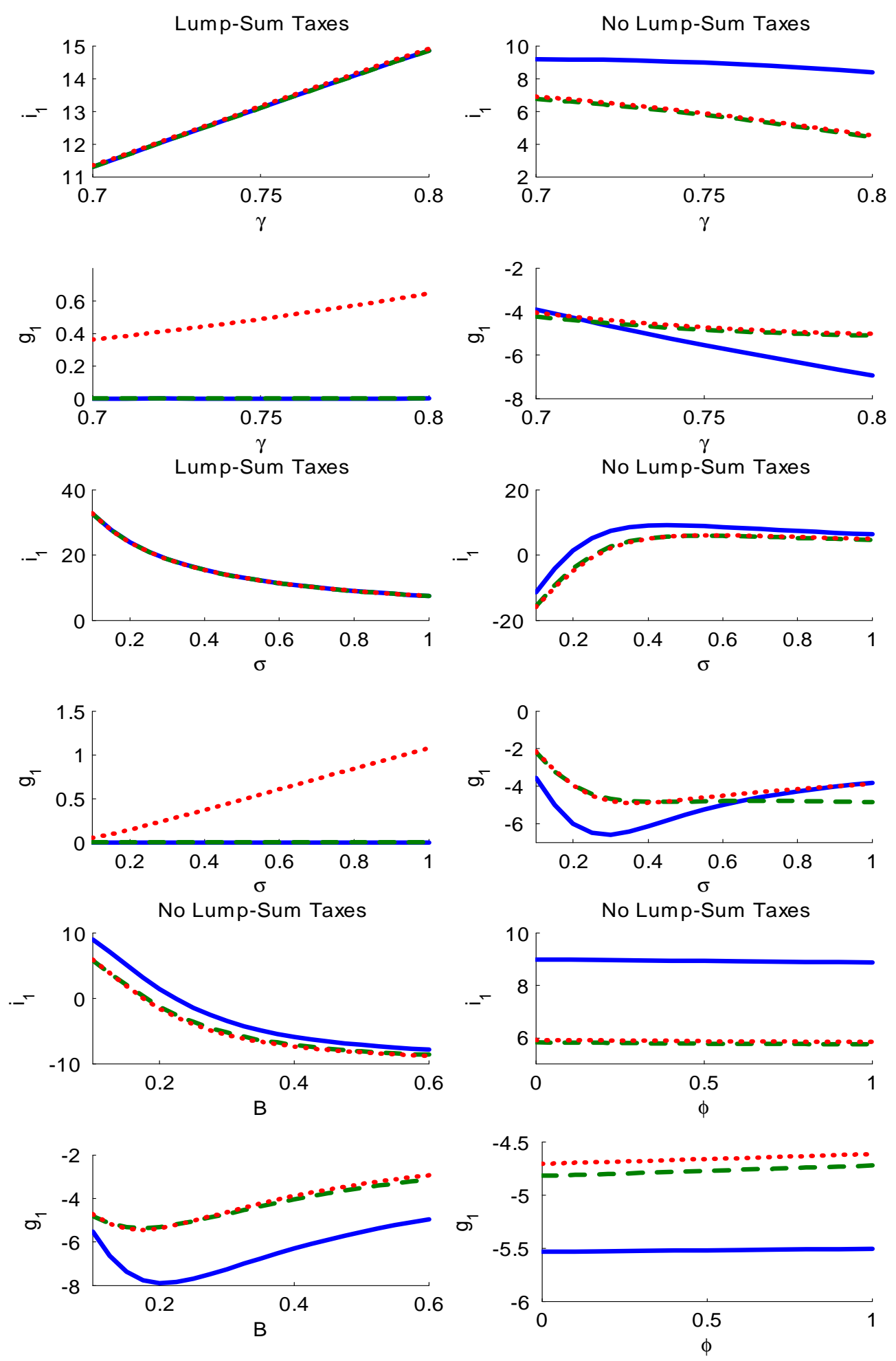


\section{Optimal Policy when Lump-Sum Taxes are not Available}

We now relax the unrealistic assumption of the existence of lump-sum taxes and explore the implications of debt accumulation for the above results. The right-hand panels of Figures 1 and 2, together with columns (4) to (6) in Table 1, present the optimal policy outcomes with government debt. Section A. outlines the optimal cooperative policy and introduces the concept of 'debt stabilisation bias'. Section B. subsequently analyses the effect of a myopic government in this setup.

\section{A. Cooperative Policy}

\section{Commitment}

The right-hand column of Figure 1 shows that optimal policy under commitment with government debt is very similar to that when lump-sum taxes are available. Monetary policy, as before, raises interest rates to reduce inflation and achieves a rapid disinflation through committing to a future path of tight policy. Fiscal policy again leaves the stabilisation of the cost-push shock to monetary policy. Without lump-sum taxes, however, government debt accumulates through higher interest payments and a fall in tax receipts (via the constant income tax rate $\tau$ ). Under optimal commitment policy, the debt stock remains permanently higher in response to the shock (see also Benigno and Woodford 2003, and Schmitt-Grohe and Uribe 2004). The reason for this 'random walk' result is as follows. When determining to what extent to reduce debt, the policymaker weighs benefits against costs. The benefit of reducing debt is that permanently higher debt leads to permanently higher interest payments, which requires a permanently lower level of government spending to ensure solvency. Lower government spending is costly, however. A large part of the cost of reducing debt is that the optimal way to do so is inflationary in this setup because it will be done, to a some extent, by lowering interest rates. This is both because interest rates have a large effect on debt - both direct (via lower interest payments) and indirect (via more tax revenues due to higher output and, with nominal debt, more inflation) - and reducing debt solely by lowering government spending would be prohibitively costly (because spending variability reduces welfare). As the benefits from permanently reducing government debt are discounted, there will be a point such that, at the margin, these gains are balanced with the cost of debt reduction and debt will remain permanently higher.

Figure 1 shows that fiscal policy is inactive on impact of the shock but permanently lowers government spending to service the permanently higher stock of debt.

Without lump-sum taxes, optimal commitment policy is time inconsistent in its control of both inflation and debt (see Leith and Wren-Lewis 2007, and Stehn and Vines 2008). The reason for this is as follows. In any period, there is a benefit from reducing debt through cutting interest rates and/or government expenditure so as to permanently cut debt service costs. We have explained above that doing so entails a cost because it is inflationary. The 
key insight is that, while the gain of cutting debt is constant over time, the cost of reducing debt in the first period is smaller than in subsequent periods. This is because, for the first period, unlike for subsequent periods, inflation expectations have already been set. A policymaker who re-optimised every period - and therefore treated inflation expectations as given every period - would face an incentive to unexpectedly lower debt in every period. The random walk under optimal commitment policy is therefore time inconsistent.

\section{Discretion}

Optimal discretionary policy in a model with government debt is therefore subject to two forms of stabilisation bias (see Stehn and Vines 2008). First, as with lump-sum taxes, optimal policy is subject to the classic 'inflation stabilisation bias'. Figure 1 shows that, as before, inflation is controlled less effectively under discretion than commitment. Second, debt does not follow a random walk under optimal discretionary policy but returns to its initial value (see Leith and Wren-Lewis 2007 and Stehn and Vines 2008). ${ }^{25}$ This 'debt stabilisation bias' is a direct consequence of the incentive to cut debt that we found under commitment. Under discretion the policymaker cannot commit to not cutting debt in future periods. The only time-consistent solution is one in which there is no incentive, at any stage, to reduce debt through unexpected changes in government spending or interest rates. As inflation, the interest rate, and spending return to their steady-state values, the only time-consistent solution is one in which debt returns to its steady-state level (i.e. equals its pre-shock value). Otherwise, as described above, there would always be an incentive to carry out an unexpected reduction in debt.

Similar to this result, BB show in their two-period model that the first-period debt stock under optimal discretionary policy is lower than under commitment. Notice, however, that $\mathrm{BB}$ impose that all accumulated debt be repaid in the second period, while it is a time consistency requirement to eventually return debt to its pre-shock level in our model.

Figure 1 and Table 1 show that the adjustment of debt towards its pre-shock level is shared by monetary and fiscal policy. Given the need to reduce debt back to its initial level, the policymaker raises interest rates substantially less than when lump-sum taxes were available. ${ }^{26}$ Unlike with lump-sum taxes, monetary policy is therefore constrained in its response to inflation by the need to control debt tightly. It now becomes optimal for fiscal policy to play an active role in the reduction of government debt and to assist the central bank in the control of inflation by cutting government spending strongly. ${ }^{27}$ We conclude that debt stabilisation bias constrains monetary policy in its response to inflation and necessitates a much more active role for fiscal policy under discretion than commitment. This finding will be important below.

\footnotetext{
${ }^{25}$ A couple of previous studies are related to this result. In Obstfeld (1991) governments want to accumulate public assets in order to reduce the incentive to generate unanticipated inflation. In the context of a liquidity trap, Eggertsson (2006) shows that a government should accumulate debt in the first period to create an incentive to deflate the debt away in following periods.

${ }^{26}$ The monetary feedback coefficient falls from 13.12 to 8.88 , see column (4) in Table 1.

${ }^{27}$ The fiscal feedback coefficient falls from zero to -5.50 , see column (4) in Table 1.
} 


\section{B. Non-Cooperative Policy with a Myopic Fiscal Authority}

We now will show that the result obtained above for an economy with lump-sum taxes - in which Nash gave rise to a fight while fiscal leadership effectively prevented it - does not continue to hold.

\section{Nash}

Figure 1 shows that the myopic government under Nash continues to spend excessively in response to the cost-push shock when lump-sum taxes are unavailable. That is, spending falls less than under the cooperative discretionary outcome in an attempt to dampen the recession which is induced by monetary tightening. ${ }^{28}$ The myopic government therefore does not sufficiently assist the central bank in the control of debt and inflation. In contrast to when lump-sum taxes were available, however, the central bank does not respond to such excess spending with higher interest rates, but instead raises the interest rate by less than the cooperative policy under discretion. ${ }^{29}$ Figure 2 shows how excess spending under Nash leads to lower interest rates than under cooperative discretionary policy and that this mechanism becomes stronger for a more myopic government. The reason for why the fight under Nash leads to lower interest rates without lump-sum taxes is the debt stabilisation bias. As discussed above, the cooperative policy under discretion raises interest rates less aggressively and cuts spending more strongly than when lump-sum taxes are available, to adjust debt back to its initial value to ensure time consistency. When the myopic government cuts spending by too little - and hence contributes insufficiently to the necessary reduction of debt - the central bank does more to ensure the required debt adjustment. Optimal monetary policy under Nash is therefore constrained in its control of inflation and raises the interest rate by less than the cooperative policy under discretion, at the cost of higher inflation. The Nash outcome clearly carries a social cost (see Table 1), because the fight not only leads to higher output and consumption variability but also to higher inflation. ${ }^{30}$ The welfare loss again rises with the degree of fiscal myopia (see Figure $2)$.

These results are related to other findings in the literature. Firstly, in their two-period model, BB show that a myopic government in a Nash game strategically raises debt in the first period to induce the central bank to create more inflation in the second period (because more debt requires a higher level of distortionary taxes and thus lower potential output in the second period, this leads the central bank to create more inflation). ${ }^{31}$ In our setup the myopic government attempts to raise debt by spending excessively but, in contrast to $\mathrm{BB}$, the central bank immediately responds by raising interest rates by less

\footnotetext{
${ }^{28}$ The fiscal feedback coefficient on the shock rises from -5.50 to -4.61 , see column (5) of Table 1 .

${ }^{29}$ The monetary feedback coefficient on the shock falls from 8.88 to 5.84, see column (5) of Table 1.

${ }^{30}$ Although difficult to see in Figure 1, the fact that first-period inflation is higher under Nash is shown in the first row of Figure 2.

${ }^{31}$ In a political-economy model without stabilisation objectives, Alesina and Tabellini (1990) show that an elected government may accumulate too much debt to constrain its successor.
} 
than the cooperative policy under discretion which, in turn, creates more inflation. The key reason for this difference is that unlike BB we do not assume that the central bank ignores the government budget constraint but instead internalises the effect of the interest rate and inflation on the public debt stock (see section F.). Secondly, the mechanism of foregoing inflation control to stabilise debt is reminiscent of the 'passive' regime obtained when fiscal policy is exogenous and monetary policy is forced to abandon inflation control to ensure intertemporal solvency (Leeper 1991). In our setup, in contrast to the 'fiscal theory of the price level', a constrained monetary response to inflation is not the consequence of exogenous fiscal insolvency, but instead the optimal discretionary outcome of the strategic interaction between a benevolent central bank and a myopic government.

\section{Fiscal Leadership}

Figures 1 and 2 show that, in sharp contrast to the setup with lump-sum taxes, fiscal leadership (FL-D) is not effective in avoiding this undesirable outcome obtained under Nash. Under both regimes the myopic authority spends excessively, which in turn induces the central bank to raise interest rates by less than the cooperative policy under discretion in order to curtail the accumulation of debt. ${ }^{32}$ Unlike with lump-sum taxes, however, a setup of fiscal leadership does not prevent the government from over-spending. Without a punishing response in the form of higher interest rates from the central bank, a regime of fiscal leadership in which the government takes the response of the central bank into account, does not deter the government from spending excessively, because it achieves its objective of dampening the first-period contraction of output and consumption. The disciplining mechanism, which was present under fiscal leadership with lump-sum taxes, has therefore been disabled by the time-consistency requirement to adjust debt back to its initial level. Nash and fiscal leadership lead to almost the same outcomes and similar welfare losses (see Table 1 and Figure 2).

\section{Robustness}

In this section we briefly consider the robustness of these results to variations of the baseline calibration. Firstly, as in the case when lump-sum taxes are available, the right-hand of Figure 3 shows that the instrument fight intensifies in an economy with stronger price rigidities (higher $\gamma$ ). Secondly, and in contrast to the case without government debt, an increase in the elasticity of substitution (higher $\sigma$ ) does not have straightforward implications for the setting of instruments. The key difference is that because interest rates have to move less to dis-inflate with a higher elasticity of substitution, a lower stock of debt is built up and the central bank is less constrained in its response to inflation.

\footnotetext{
${ }^{32}$ The fiscal and monetary feedback coefficients on the shock equal -4.72 and 5.74 respectively, see column (6) in Table 1.
} 
The bottom two rows of Figure 3 consider alternative debt calibrations. Firstly, we show that the qualitative results continue to hold with higher steady-state debt (larger $B$ ). For optimal cooperative policy under discretion, Stehn and Vines (2008) demonstrate that the constraint which debt stabilisation bias imposes on monetary policy becomes stronger in economies with higher steady-state debt. Figure 3 shows that a myopic government under Nash and fiscal leadership constrains monetary policy more severely in raising interest rates for higher debt calibrations and can even force the central bank to cut interest rates (and hence violate the Taylor principle) in response to the cost-push shock. Secondly, Figure 3 shows that the results are largely unchanged for different combinations of nominal and indexed debt (denoting the share of nominal debt with $\phi$ ). ${ }^{33}$ While interest rates are raised more strongly with a higher share of indexed debt under Nash and fiscal leadership, the effect is very small. This is because even with nominal debt the effect of lower interest rates on debt via reduced interest payments and higher output are far greater than the effect of surprise inflation (see also Leith and Wren-Lewis 2007).

The main result of this section is sensitive, however, to the introduction of inflation persistence. Stehn and Vines (2008) show that inflation persistence softens the pressure that government debt places on the central bank in responding to inflation. With significant inflation persistence, a Nash game no longer leads to lower interest rates than the cooperative policy under discretion, as the inflationary consequences would be prohibitively costly (results are not shown here for brevity). With inflation persistence, fiscal leadership regains some of its effectiveness in preventing the myopic government from spending excessively.

\section{Optimal Institutions}

This section discusses how appropriately designed institutions can improve the non-cooperative outcomes and raise social welfare. With regard to the design of monetary institutions, the 'optimal delegation' literature has analysed the merits of appointing a conservative central bank when monetary policymakers are unable to commit (Rogoff 1985, Clarida et al 1999). In the context of the Stability and Growth Pact (SGP) in particular, a large literature has explored the benefits of imposing debt or deficit ceilings onto governments (see Beetsma and Debrun 2004 for a survey).

When lump-sum taxes are available, we have shown that a setup of fiscal leadership leads to the same outcome as the optimal cooperative policy under discretion. It is therefore sufficient to ensure that the myopic government can act as the leader with respect to the central bank. A credible budget process, which ensures that the government moves first, could serve this role. Without lump-sum taxes, however, we have shown that both Nash and fiscal leadership give rise to socially costly outcomes. In principle, the delegation of fiscal policy to a benevolent fiscal policy committee, which does not suffer from myopia (i.e.

\footnotetext{
${ }^{33}$ The stock of indexed debt, $d_{t}$, is defined as $d_{t}=b_{t}-\pi_{t}$.
} 
$p=1$ ), could reproduce the cooperative outcome under discretion. ${ }^{34}$ Given the political problems surrounding this approach, however, we regard this option as practically infeasible. Instead we will consider the effect of imposing a debt penalty onto the myopic government (section A.) and of appointing a conservative central bank (section B.). ${ }^{35}$

\section{A. A Debt Penalty}

The aim of a debt penalty is to discipline the government by raising the marginal cost of public spending. ${ }^{36} \mathrm{BB}$, for example, analyse the effect of a debt penalty. In their model the myopic government accumulates too much debt in the first period because doing so requires higher distortionary taxes in the second period to repay the debt, which in turn induces the central bank to create more inflation. A debt target induces the myopic government to accumulate less debt which in turn enhances the credibility of the central bank in the second period. In BB, a debt target raises welfare but falls short of replicating the cooperative commitment benchmark.

To evaluate the effect of a debt penalty, we constrain the myopic government to maximise its familiar objective function plus a penalty on the deviation of debt from its steady-state level (i.e. the new objective function takes the form $W_{s}^{F}+\lambda_{B} b_{s}^{2}$ ). This penalty can be interpreted as financial sanctions on the government for missing the debt target (e.g. the Excessive Deficit Procedure of the SGP). The central bank continues to maximise the social welfare function. Figure 4 shows that an optimally chosen debt penalty is highly effective under both Nash and fiscal leadership. ${ }^{37}$ We discussed above how debt accumulates as interest rates rise and output falls in response to the cost-push shock. An optimally-chosen debt penalty $\left(\lambda_{B}=\lambda_{B}^{*}\right)$ successfully prevents the myopic government from spending excessively, under both Nash and fiscal leadership (see left-hand panel of Figure 4). The key mechanism through which the debt penalty is beneficial, however, is that is raises the fiscal feedback on debt (Figure 4 shows that government spending is now slowly smoothed to zero). ${ }^{38}$ Such an 'inertial' fiscal response leads to a better equilibrium, for the following reason. Recall that the inability to commit is costly because it requires debt to be adjusted back to its pre-shock level and that most of this adjustment is done in the first period. This requirement prevent the central bank from raising interest rates as much as it would if lump-sum taxes were available. A debt penalty forces fiscal policy to lower spending during the whole transition period in which debt exceeds its pre-shock level and therefore relieves the pressure on monetary policy to reduce debt. Anticipating that fiscal policy will be contractionary for a prolonged period of time, the central bank is able

\footnotetext{
${ }^{34}$ Ball (1997), Blinder (1997) and Wyplosz (2005), for example, discuss the delegation of fiscal policy.

${ }^{35}$ Following most of the literature, including BB, we study institutional arrangements that are exogenously imposed onto the policymakers, rather than endogenously chosen by the policymakers as part of the policy problem.

${ }^{36}$ Stehn (2007) analyses the benefits of a debt penalty in the simple model used by KSV.

${ }^{37}$ For the baseline calibration, the optimal debt penalty is approximately equal to one tenth of the weight on consumption (i.e. $\lambda_{B}^{*} \approx \frac{1}{10} \lambda_{c}$ ).

${ }^{38}$ Blake and Kirsanova (2006) show that penalising changes in instruments has a similar effect.
} 
Figure 4: Optimal policy without lump-sum taxes and a myopic government with a debt penalty.

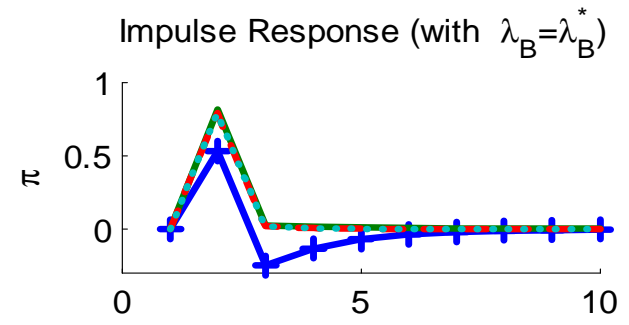

First-Period Response (Changing $\lambda_{B}$ )
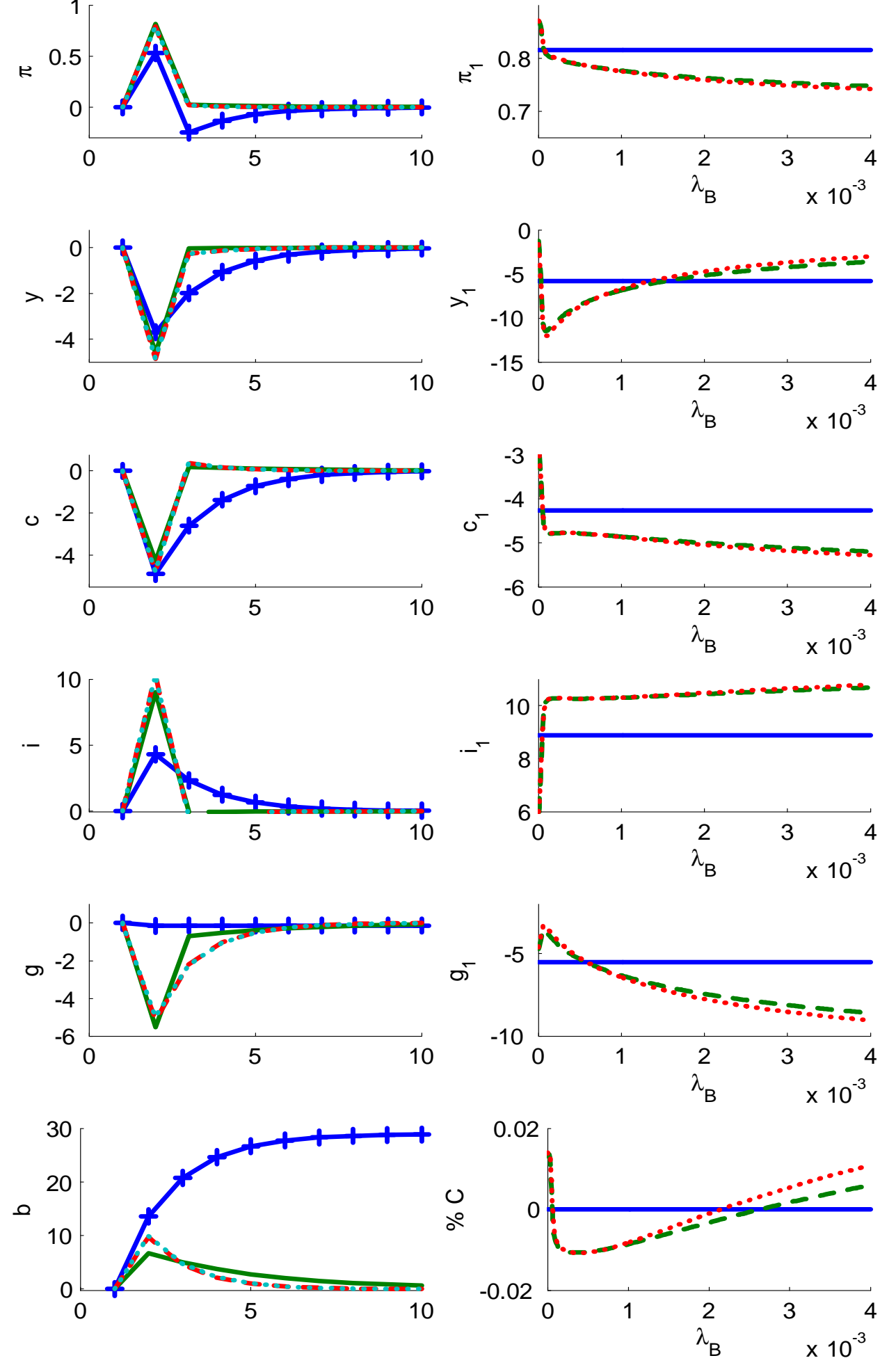

$\leftarrow$ Cooperation (Commitment)

Cooperation (Discretion) 
to raise interest considerably more in the first period to fight inflation than without the debt penalty (and even more than the cooperative policy under discretion). The outcome is a faster disinflation and an improvement in welfare.

In fact, the welfare losses under Nash and fiscal leadership even fall below that with the cooperative policy under discretion (see right-hand panel of Figure 4). This mechanism is an example of the theory of the 'second best': by imposing an additional distortion onto an already suboptimal outcome, a debt penalty offsets the original distortion and raises welfare, but as in BB, does not fully reproduce the commitment outcome. Figure 4 also shows that debt penalties may be detrimental if they are too strong as they lead to too tight control of debt. Given the debate about relative the merits of debt versus deficit targets in the context of Europe's fiscal framework, it is interesting to note that a deficit penalty would not be effective in raising welfare because it would not provide an inter-temporal incentive mechanism for fiscal policy.

\section{B. A Conservative Central Bank}

While the benefits of delegating monetary policy to a conservative central bank to offset the distortions associated with discretionary monetary policymaking are well understood, the case with fiscal policy and public debt is more complex. BB, for example, show that the central bank should be made anti-conservative when the government is myopic (i.e. the central bank should be assigned a relative inflation weight that is smaller than in the social welfare function). If, however, a debt penalty has already been imposed onto the myopic government, a conservative central bank will raise welfare (and even reproduce the cooperative commitment solution).

A similar result holds in our model when lump-sum taxes are not available. We assume that the central bank is mandated to maximise social welfare but is required to attach a weight $\eta \lambda_{\pi}$ on inflation (i.e. the central bank is conservative if $\eta>1$ ). In the absence of a debt penalty, the left-hand panel in Figure 5 shows that appointing a conservative central bank further raises the problems caused by a myopic government under both Nash and fiscal leadership. A more inflation-averse policymaker raises interest rates more aggressively in response to the shock, which induces the myopic government to raise spending by even more than it did with a benevolent central bank. As in BB, Figure 5 shows that a mildly anti-conservative central bank $\left(\eta^{*}<1\right)$ can raise welfare, because it raises interest rates less strongly in response to the shock and hence reduces the incentive for excess government spending. When an optimal debt penalty is already in place $\left(\lambda_{B}=\lambda_{B}^{*}\right)$, the central bank should be made mildly conservative $\left(\eta^{*}>1\right)$ under both Nash and fiscal leadership (see right-hand panel of Figure 5). Given that fiscal policy is induced to control the debt stock more tightly, interest rates can rise by more and control inflation more tightly. The optimal degree of conservatism is small because too large an emphasis on inflation comes at the cost of sub-optimally high consumption and output volatility. While appointing a conservative central bank in the presence of a debt penalty raises welfare, the gains are small. Intuitively, as the cost stems from distorted fiscal objectives, changing the incentives 
Figure 5: Optimal policy without lump-sum taxes and a myopic government for different degrees of monetary conservatism $(\eta)$.
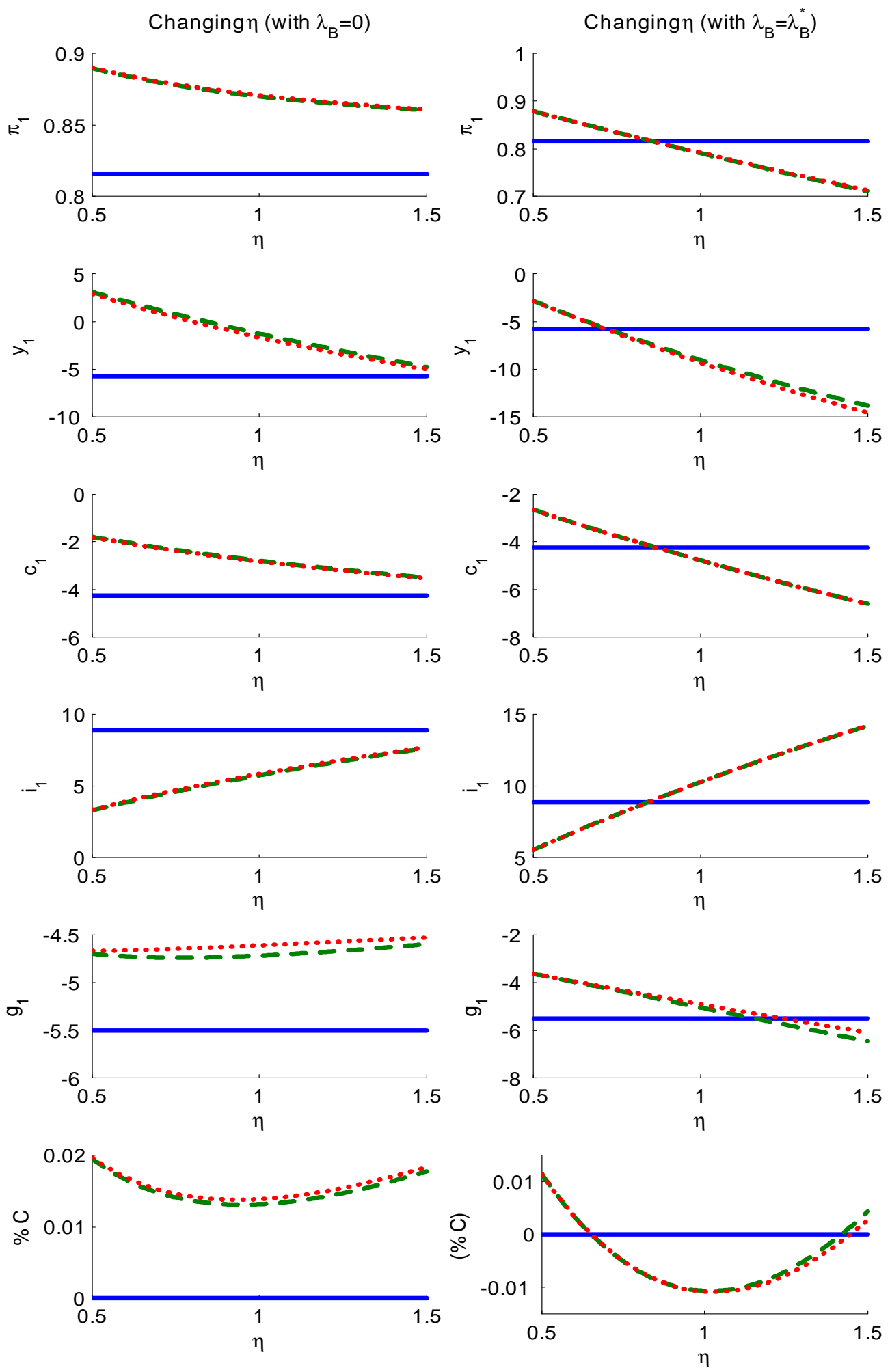

Cooperation (Discretion) - - Fiscal leadership $\ldots . .$. Nash 
of the government, rather than the central bank, is more effective.

\section{Conclusion}

This paper has made two contributions to the analysis of the strategic interactions between monetary and fiscal policy. First, we showed that the result of the recent literature - that fiscal leadership can effectively avoid the Nash outcome of too much spending and excessively high interest rates - continues to hold in a New Keynesian model under optimal discretionary policy, provided that lump-sum taxes are available. Second, we showed that this result breaks down when lump-sum taxes are unavailable. With government debt, the Nash equilibrium still entails too much public spending but leads to lower interest rates than the cooperative policy under discretion. This is because debt has to be returned to its pre-shock level under discretionary policy, and with the myopic government contributing insufficiently to the required adjustment, monetary policy takes on the additional reduction of debt. A setup of fiscal leadership is not effective in avoiding this socially costly outcome. We then discussed institutional arrangements to help resolve this problem. We showed that imposing a debt penalty onto the myopic government under either Nash or fiscal leadership raises welfare significantly, while appointing a conservative central bank is less effective. These findings highlight the benefits of constraining governments with debt targets in countries with independent central banks.

In future work we plan to extend the analysis in this paper in two ways. First, our model assumed government debt to have a one-period maturity, which gives monetary policy high leverage over interest payments and hence creates a strong incentive to lower interest rates to reduce debt. This setup may therefore overstate the distortion which a myopic

government causes when lump-sum taxes are not available. It has recently been shown that the optimal fiscal and monetary policy under commitment can be made time consistent if the maturity structure of debt can be chosen such that the marginal benefit of a surprise inflation balances the marginal cost (Persson et al 2006). With such an optimally chosen debt structure, a monetary tightening sufficient to offset an excessive fiscal expansion under Nash - and hence deterring the myopic government from spending too much under fiscal leadership - may again be possible. Second, it is of particular interest to test for empirical support of the predictions of our model. Recent empirical work has indicated that the response of monetary policy to inflation can be constrained by the behaviour of fiscal policy in emerging market economies (e.g. Baig et al 2006, Mitra 2007). To what extent this result can be explained by the strategic interactions between the central bank and the government, and how the institutional setup that governs their interaction matters, is an interesting question for future work. 


\section{Appendix}

\section{A. Social Welfare}

The derivations in this Section are based on Kirsanova and Wren-Lewis (2007). The intra-temporal utility function in (14) can be written as:

$$
W_{s}=u\left(C_{s}\right)+f\left(G_{s}\right)-\int_{0}^{1} v\left(H_{s}(z)\right) d z
$$

Following Woodford (2003a), we linearise $W_{s}$ around its equilibrium using $\hat{X}_{t}=\ln \left(X_{t} / X\right)$ :

$$
\begin{aligned}
W_{s} & =C u_{C}(C)\left(\hat{C}_{s}+\frac{1}{2}\left(1-\frac{1}{\sigma}\right) \hat{C}_{s}^{2}\right)+G f_{G}(G)\left(\hat{G}_{s}+\frac{1}{2}\left(1-\frac{1}{\sigma}\right) \hat{G}_{s}^{2}\right) \\
& -Y v_{y}(Y)\left(\hat{Y}_{s}+\frac{1}{2}\left(1+\frac{1}{\psi}\right) \hat{Y}_{s}^{2}+\frac{1}{2}\left(\frac{1}{\psi}+\frac{1}{\varepsilon}\right) v_{a r} \hat{y}_{s}(z)\right)+O(3)+\text { tip }
\end{aligned}
$$

where $O(3)$ denotes terms of higher than second order and tip denotes terms independent of policy. Further, we linearise the aggregate demand equation (6):

$$
\hat{C}_{s}=\frac{1}{\theta}\left(\hat{Y}_{s}-(1-\theta) \hat{G}_{s}-\theta \frac{1}{2} \hat{C}_{s}^{2}-\frac{1}{2}(1-\theta) \hat{G}_{s}^{2}+\frac{1}{2} \hat{Y}_{s}^{2}\right)+O(3)+\text { tip }
$$

Substituting this expression into (18) we obtain:

$$
\begin{aligned}
W_{s} & =\theta u_{C}\left[\left(1-\frac{v_{y}}{u_{C}}\right) \hat{Y}_{s}-(1-\theta)\left(1-\frac{f_{G}}{u_{C}}\right) \hat{G}_{s}-\frac{\theta}{2 \sigma} \hat{C}_{s}^{2}-\frac{(1-\theta)}{2}\left(1+\frac{f_{G}}{u_{C}} \frac{(1-\sigma)}{\sigma}\right) \hat{G}_{s}^{2}\right. \\
& \left.-\frac{1}{2}\left(\frac{v_{y}}{u_{C}} \frac{1+\psi}{\psi}-1\right) \hat{Y}_{s}^{2}-\frac{1}{2} \frac{v_{y}}{u_{C}}\left(\frac{1}{\varepsilon}+\frac{1}{\psi}\right) \operatorname{var}_{z} \hat{y}_{s}(z)\right]+O(3)+\text { tip }
\end{aligned}
$$

The next step is to eliminate the linear terms in output and government spending. The government is assumed to eliminate both the distortions resulting from monopolistic competition and the distortions resulting from income taxation with a lump sum that ensures $\frac{f_{G}}{u_{C}}=\frac{v_{y}}{u_{C}}=1$. Substituting and re-writing the loss function in 'gap' form (denoting $\left.x_{t}=\hat{X}_{t}-\hat{X}_{t}^{n}\right)$ :

$$
W_{s}=-\theta u_{C}\left[\frac{\theta}{2 \sigma} c_{s}^{2}+\frac{(1-\theta)}{2 \sigma} g_{s}^{2}+\frac{1}{2 \psi} y_{s}^{2}+\frac{1}{2}\left(\frac{1}{\varepsilon}+\frac{1}{\psi}\right) \operatorname{var}_{z} \hat{y}_{s}(z)\right]+O(3)+\text { tip }
$$

Finally, Woodford (2003a) has shown how to express $\operatorname{var}_{z} \hat{y}_{s}(z)$ in terms of inflation variability. The assumed CES preferences over differentiated goods imply:

$$
\operatorname{var}_{z} \hat{y}_{s}(z)=\varepsilon^{2} \Delta_{t}
$$


where $\Delta_{t}=\operatorname{var}_{z} \hat{p}_{s}(z)$ denotes the degree of price dispersion. Woodford (2003a) has shown that price dispersion evolves according to:

$$
\Delta_{t}=\gamma \Delta_{t-1}+\frac{\gamma}{1-\gamma} \pi_{t}^{2}
$$

Integrating (21) forward and taking the discounted value of these terms using the social discount rate, $\beta$, Woodford (2003a) has shown that:

$$
\sum_{s=0}^{\infty} \beta^{s} \Delta_{s}=\frac{\gamma}{(1-\gamma \beta)(1-\gamma)} \sum_{s=0}^{\infty} \beta^{s} \pi_{s}^{2}+O(3)+t i p
$$

Substituting (22) into (19) we obtain (15) in the main text.

\section{B. Policy Myopia}

To find a second-order approximation to the myopic policymaker's utility maximisation problem, we follow the same steps as for the social welfare function above until we obtain an expression identical to (19). We again want to express $\operatorname{var}_{z} \hat{y}_{s}(z)$ in terms of inflation variability and the evolution of price dispersion, (21), is the same as before. Integrating (21) forward and taking the discounted value of these terms using $p \beta$ we obtain:

$$
\sum_{s=0}^{\infty}(p \beta)^{s} \Delta_{s}=\frac{\gamma}{(1-\gamma p \beta)(1-\gamma)} \sum_{s=0}^{\infty}(p \beta)^{s} \pi_{s}^{2}+O(3)+\text { tip }
$$

Substituting (23) into (19) we obtain (16) in the main text.

\section{Solving the Model}

In this second Appendix we outline the solution method for finding optimal policy. Let us write equations (10)-(13) as:

$$
\left[\begin{array}{c}
X_{1, t+1} \\
E_{t} X_{2, t+1}
\end{array}\right]=\left[\begin{array}{cc}
A_{11} & A_{12} \\
A_{21} & A_{22}
\end{array}\right]\left[\begin{array}{c}
X_{1, t} \\
X_{2, t}
\end{array}\right]+\left[\begin{array}{ll}
B_{11} & B_{12} \\
B_{21} & B_{22}
\end{array}\right]\left[\begin{array}{c}
u_{t}^{L} \\
u_{t}^{F}
\end{array}\right]+\left[\begin{array}{c}
\varepsilon_{t+1} \\
0_{n_{2} \times 1}
\end{array}\right]
$$

where $X_{1, t}$ is a $n_{1} \times 1$ vector of predetermined variables with initial conditions $X_{1,0}$ given, $X_{2, t}$ is a $n_{2} \times 1$ vector of forward-looking variables and $\varepsilon_{t+1}$ is a white noise process. $u_{t}^{L}$ and $u_{t}^{F}$ are the instruments of the leader and follower. We define the vector $X_{t}=\left(X_{1, t}^{\prime}, X_{2, t}^{\prime}\right)^{\prime}$ and the instrument vector $u_{t}=\left(u_{t}^{L \prime}, u_{t}^{F^{\prime}}\right)^{\prime}$. For our model we have:

$$
X_{1, t+1}=\left(\mu_{t+1}, b_{t+1}\right)^{\prime}, \quad X_{2, t+1}=\left(\pi_{t+1}, c_{t+1}\right)^{\prime}, \quad u_{t}=\left(u_{t}^{L \prime}, u_{t}^{F \prime}\right)^{\prime}=\left(i_{t}, g_{t}\right)^{\prime}
$$




\section{Optimal Cooperative Policy}

This section is taken from Soderlind (1999), which in turn is based on Currie and Levine (1993).

Commitment The objective function under commitment can be written as a constrained loss function:

$$
w_{C}=E_{0} \sum_{s=t}^{\infty} H_{s}^{C}
$$

with

$$
H_{s}^{C}=\beta^{s-t}\left[X_{t}^{\prime} Q X_{t}+2 X_{t}^{\prime} U u_{t}+u_{t}^{\prime} R u_{t}+\rho_{t+1}^{\prime}\left(A X_{t}+B u_{t}+E_{t+1}-X_{t+1}\right)\right]
$$

where $Q, U$ and $R$ are appropriately defined weight matrices and $\rho_{t+1}$ is a n-dimensional Lagrange multiplier. Its first $n_{1}$ elements are given by the vector $\rho_{1, t}$ and the remaining $n_{2}$ elements by $\rho_{2, t}$. The first order conditions are given by

$$
\frac{\partial H_{s}^{C}}{\partial u_{s}}=0, \quad \frac{\partial H_{s}^{C}}{\partial X_{t}}=0, \quad \frac{\partial H_{s}^{C}}{\partial \rho_{t+1}}=0
$$

Using the initial conditions $X_{1,0}$ and $\rho_{2,0}=0$ and the generalised Schur decomposition, the evolution of the 'jump' variables under optimal policy is given by:

$$
\left(X_{2, t}, u_{t}, \rho_{1, t}\right)^{\prime}=\Phi\left(X_{1, t}, \rho_{2, t}\right)^{\prime}
$$

The evolution of the state variables of the system under optimal policy is given by:

$$
\left(X_{1, t+1}, \rho_{2, t+1}\right)^{\prime}=\Psi\left(X_{1, t}, \rho_{2, t}\right)^{\prime}+E_{t+1}
$$

Equations (25) and (24) together with the initial conditions $X_{1,0}$ and $\rho_{2,0}=0$ provide a complete description of the evolution of the economy.

Discretion The policymaker takes the expectations of the private agents as given under discretion. Given the linear quadratic setup, the reaction function of the public is linear:

$$
X_{2, t}=-G X_{1, t}-K u_{t}
$$

where the matrices $G$ and $K$ are unknown. Substituting for (26) and forming the constrained period loss function:

$$
\begin{aligned}
H_{s}^{D} & =\beta^{t-s}\left[X_{s}^{\prime} Q X_{s}+2 X_{s}^{\prime} U u_{s}+u_{s}^{\prime} R u_{s}\right. \\
& \left.+\mu_{s+1}^{\prime}\left(\left(A_{11}-G A_{12}\right) X_{1, s}+\left(B_{1}-A_{12} K\right) u_{s}+\varepsilon_{s+1}-X_{1, s+1}\right)\right]
\end{aligned}
$$


where $\mu_{t+1}$ is a vector of Lagrange multipliers. The first order conditions with respect to $u_{s}, X_{1, s}$ and $\mu_{s+1}$ are given by:

$$
\frac{\partial H_{s}^{D}}{\partial u_{s}}=0, \quad \frac{\partial H_{s}^{D}}{\partial X_{1, s}}=0, \quad \frac{\partial H_{s}^{D}}{\partial \mu_{s+1}}=0
$$

The solution of these first order conditions converges to:

$$
\begin{aligned}
u_{t} & =-F X_{1, t} \\
X_{2, t} & =C X_{1, t}
\end{aligned}
$$

Using the initial conditions, the matrices $F$ and $C$ can be found using an iterative numerical procedure.

\section{Optimal Non-Cooperative Policy under Discretion}

This section is taken from Blake and Kirsanova (2006), who have extended Currie and Levine (1993) to solve for optimal non-cooperative policy under discretion.

Fiscal Leadership The first step consists of guessing the reaction function of the private agents (the ultimate follower). Using the generalised Schur decomposition, the current value of the (non-instrument) jump variables as a function of the predetermined and instrument variables is found:

$$
X_{2, t}=-J X_{1, t}-K^{F} u_{t}^{F}-K^{L} u_{t}^{L}
$$

where the matrices $J, K^{F}$ and $K^{L}$ are unknown. The follower maximises his objective function with respect to $u_{t}^{F}$, taking $u_{t}^{L}$ and $X_{2, t}$ as given but internalising the dependence of $X_{2, t}$ on $u_{t}^{L}$ and $u_{t}^{F}$ through (27). Writing the period constrained welfare loss as:

$$
H_{s}^{F}=\beta_{F}^{s-t}\left[X_{s}^{\prime} Q^{F} X_{s}+2 X_{s}^{\prime} U^{F} u_{s}+u_{s}^{\prime} R^{F} u_{s}+\lambda_{s+1}^{\prime}\left(A_{11} X_{1, s}+A_{12} X_{2, s}+B_{1} u_{s}-X_{1, s+1}\right)\right]
$$

where $\lambda_{t+1}$ is a vector of Lagrange multipliers and $\beta_{F}$ the discount rate of the follower. The first order conditions are:

$$
\begin{aligned}
\frac{\partial H_{s}^{F}}{\partial u_{s}^{F}}+\frac{\partial H_{s}^{F}}{\partial X_{2, s}} \frac{\partial X_{2, s}}{\partial u_{s}^{F}} & =0 \\
\frac{\partial H_{s}^{F}}{\partial X_{1, s}}+\frac{\partial H_{s}^{F}}{\partial X_{2, s}} \frac{\partial X_{2, s}}{\partial X_{1, s}}+\left(\frac{\partial H_{s}^{F}}{\partial u_{s}^{L}}+\frac{\partial H_{s}^{F}}{\partial X_{2, s}} \frac{\partial X_{2, s}}{\partial u_{s}^{L}}\right) \frac{\partial u_{s}^{L}}{\partial X_{1, s}}+\frac{\partial H_{s-1}^{F}}{\partial X_{1, s}} & =0 \\
\frac{\partial H_{s}^{F}}{\partial \lambda_{s+1}} & =0
\end{aligned}
$$


The values of $X_{1, s}$ are chosen subject to the behaviour of the ultimate follower and the evolution of the economy:

$$
\frac{\partial X_{2, s}}{\partial X_{1, s}}=-J^{\prime}, \quad \frac{\partial X_{2, s}}{\partial u_{s}^{F}}=-K^{F \prime}, \quad \frac{\partial X_{2, s}}{\partial u_{s}^{L}}=-K^{L \prime}
$$

The system can be solved as a function of $X_{1, t}$ and $u_{t}^{L}$ to obtain a linear rule:

$$
u_{t}^{F}=-F^{F} X_{1, t}-L u_{t}^{L}
$$

where the matrices $F^{F}$ and $L$ depend on $J, K^{F}$ and $K^{L}$ of the ultimate follower. Finally, the Stackelberg leader chooses a point on the follower's reaction function to minimise his loss function and also takes into account the response of the ultimate follower. Define:

$$
H_{s}^{L}=\beta_{L}^{s-t}\left[X_{s}^{\prime} Q^{L} X_{s}+2 X_{s}^{\prime} U^{L} u_{s}+u_{s}^{\prime} R^{L} u_{s}+\kappa_{s+1}^{\prime}\left(A_{11} X_{1, s}+A_{12} X_{2, s}+B_{1} u_{s}-X_{1, s+1}\right)\right]
$$

where $\kappa_{s+1}$ is a vector of Lagrange multipliers and $\beta_{L}$ the discount rate of the leader. The first order conditions are:

$$
\begin{aligned}
& \frac{\partial H_{s}^{L}}{\partial u_{s}^{L}}+\frac{\partial H_{s}^{L}}{\partial X_{2, s}} \frac{\partial X_{2, s}}{\partial u_{s}^{L}}+\left(\frac{\partial H_{s}^{L}}{\partial u_{s}^{F}}+\frac{\partial H_{s}^{L}}{\partial X_{2, s}} \frac{\partial X_{2, s}}{\partial u_{s}^{F}}\right) \frac{\partial u_{s}^{F}}{\partial u_{s}^{L}}=0 \\
& \frac{\partial H_{s}^{L}}{\partial X_{1, s}}+\frac{\partial H_{s}^{L}}{\partial X_{2, s}} \frac{\partial X_{2, s}}{\partial X_{1, s}}+\left(\frac{\partial H_{s}^{L}}{\partial u_{s}^{F}}+\frac{\partial H_{s}^{L}}{\partial X_{2, s}} \frac{\partial X_{2, s}}{\partial u_{s}^{F}}\right) \frac{\partial u_{s}^{F}}{\partial X_{1, s}}+\frac{\partial H_{s-1}^{L}}{\partial X_{1, s}}=0 \\
& \frac{\partial H_{s}^{L}}{\partial \kappa_{s+1}}=0
\end{aligned}
$$

Additionally the leader takes into account the behaviour of the ultimate follower (27), the evolution of the economy and the reaction function of the follower (28):

$$
\frac{\partial u_{s}^{F}}{\partial u_{s}^{L}}=-L^{\prime}, \quad \frac{\partial u_{s}^{F}}{\partial X_{1, s}}=-F^{F^{\prime}}
$$

The optimal policy rule for the leader can be expressed as a linear rule:

$$
u_{t}^{L}=-F^{L} X_{1, t}
$$

where the matrix $F^{L}$ depends on $J, K^{F}$ and $K^{L}$ of the ultimate follower and $F^{F}$ and $L$ of the follower. These matrices are then found using an iterative numerical procedure.

Nash In a Nash equilibrium neither policymakers takes into account the reaction function of the other player but instead treats it parametrically. The first order conditions are identical for both players $(i=\{F, L\})$. The constrained period loss function is given by:

$$
H_{s}^{i}=\beta_{i}^{s-t}\left[X_{s}^{\prime} Q^{i} X_{s}+2 X_{s}^{\prime} U^{i} u_{s}+u_{s}^{\prime} R^{i} u_{s}+\kappa_{s+1}^{i \prime}\left(A_{11} X_{1, s}+A_{12} X_{2, s}+B_{1} u_{s}-X_{1, s+1}\right)\right]
$$


with first order conditions

$$
\begin{aligned}
\frac{\partial H_{s}^{i}}{\partial u_{s}^{i}}+\frac{\partial H_{s}^{i}}{\partial X_{2, s}} \frac{\partial X_{2, s}}{\partial u_{s}^{i}} & =0 \\
\frac{\partial H_{s}^{i}}{\partial X_{1, s}}+\frac{\partial H_{s}^{i}}{\partial X_{2, s}} \frac{\partial X_{2, s}}{\partial X_{1, s}}+\left(\frac{\partial H_{s}^{i}}{\partial u_{s}^{j}}+\frac{\partial H_{s}^{i}}{\partial X_{2, s}} \frac{\partial X_{2, s}}{\partial u_{s}^{j}}\right) \frac{\partial u_{s}^{j}}{\partial X_{1, s}}+\frac{\partial H_{s-1}^{i}}{\partial X_{1, s}} & =0 \\
\frac{\partial H_{s}^{i}}{\partial \kappa_{s+1}^{i}} & =0
\end{aligned}
$$

Assuming that the reaction function of the two players are given by:

$$
u_{t}^{i}=-F^{i} X_{1, t}
$$

The optimal feedback coefficients are then found using an iterative procedure. 


\section{References}

Alesina, A. and G. Tabellini (1987): "Rules and discretion with non-coordinated monetary and fiscal policies", Economic Inquiry, October 1987, 619-630.

—, (1990): "A Positive Theory of Fiscal Deficits and Government Debt", The Review of Economic Studies, Vol. 57, No. 3., 403-414.

Baig, T., M. Kumar, G. Vasishtha, and E. Zoli (2006): "Fiscal and Monetary Nexus in Emerging Market Economies: How Does Debt Matter?", IMF Working Paper, $06 / 184$.

Ball, L. (1997): "A proposal for the next macroeconomic reform", Victoria Economic Commentaries, Vol 14 No 1, 1-7.

Beetsma, R. and A. Bovenberg (1997a): "Designing fiscal and monetary institutions in a second best world", European Journal of Political Economy, Vol 13, 53-79.

—, (1997b): "Central bank independence and public debt policy", Journal of Economic Dynamics and Control 21, 873-894.

Beetsma, R. and X. Debrun (2004): "The interaction between monetary and fiscal policies in a monetary union: a review of recent literature", in: R. Beetsma, C. Favero, A. Missale, V.A. Muscatelli, P. Natale and P. Tirelli (eds.), Fiscal Policies, Monetary Policies and Labour Markets, Cambridge University Press, Cambridge.

Benigno, P. and M. Woodford (2003): "Optimal Monetary and Fiscal Policy: A Linear-Quadratic Approach,", NBER Macroeconomics Annual, 2003.

Blake, A. and T. Kirsanova (2006): "Monetary and fiscal policy interactions: Optimal delegation and the value of leadership", Mimeo, University of Essex.

Blinder, A. (1997): "Is Government Too Political?", Foreign Affairs, Vol. 76, no. 6 (Nov/Dec 1997), 115-126.

Castellani, F. and X. Debrun (2005): "Designing Macroeconomic Frameworks: A positive analysis of monetary and fiscal delegation", International Finance, Vol. 8, No. 1, 87-117.

Clarida, R., J. Gali and M. Gertler (1999): "The science of monetary policy: a New Keynesian perspective", Journal of Economic Literature, 37, 1661-1707.

Cukierman, A., S. Edwards and G. Tabellini (1992): "Seigniorage and Political Instability", American Economics Review, 82, 537-555.

Currie, D. A. and P. Levine (1993): Rules, Reputation and Macroeconomic Policy Coordination, Cambridge University Press. 
Dixit, A. and L. Lambertini (2003): "Interactions of commitment and discretion in monetary and fiscal policies", American Economic Review, 93, 1522-1542.

Eggertsson, G. (2006): "The Deflation Bias and Committing to Being Irresponsible", Journal of Money, Credit, and Banking, Vol. 38, No. 2, 283-322.

Kirsanova, T., J. Stehn and D. Vines (2005): "The Interactions of Monetary and Fiscal Policy", Oxford Review of Economic Policy, 21 (1).

Kirsanova, T. and S. Wren-Lewis. (2007). "Optimal fiscal feedback in an economy with nominal rigidities." Department of Economics Series Working Paper, No. 306, University of Oxford.

Lambertini, L. (2006): "Monetary-fiscal interactions with a conservative central bank", Scottish Journal of Political Economy, Vol. 53, No. 1, 90-128.

Leeper, E. (1991). "Equilibria under 'active' and 'passive' monetary and fiscal policies", Journal of Monetary Economics 27, 129-47.

Leith, C. and S. Wren-Lewis (2007): "Fiscal sustainability in a New Keynesian model", Department of Economics Series Working Paper, No. 310, University of Oxford.

McCallum, B. (1995): "Two Fallacies Concerning Central-Bank Independence", The American Economic Review, Vol. 85, No. 2, 207-211.

Mitra, S. (2007). "Is the Quantity of Government Debt a Constraint for Monetary Policy?", IMF Working Paper, No. 07/62.

Obstfeld, M. (1991): "Dynamic seigniorage theory: An exploration", CEPR Discussion Paper, No. 519.

Persson, M., T. Persson and Lars E. O. Svensson (2006): "Time consistency of fiscal and monetary policy: A solution", Econometrica, Vol. 74, No. 1, 193-212.

Rogoff, K. (1985): "The Optimal Degree of Commitment to an Intermediate Monetary Target", Quarterly Journal of Economics, Vol. 100. No. 4, 1169-89.

—, (1990): "Equilibrium Political Budget Cycles", The American Economic Review, Vol. 80, No. 1, 21-36.

Schmitt-Grohe, S. and M. Uribe (2004): "Optimal Simple And Implementable Monetary and Fiscal Rules", Journal of Monetary Economics, forthcoming.

Soderlind, P. (1999): "Solution and estimation of RE macromodels with optimal policy", European Economic Review, 43, 813-823.

Stehn, J. and D. Vines (2008): "Debt Stabilisation Bias and the Taylor Principle: Optimal Policy in a New Keynesian Model with Government Debt and Inflation Persistence", CEPR Discussion Paper, No. 6696. 
Stehn, J. (2007): "Debt bias in a simple Five-Equation model", Mimeo, University of Oxford.

Woodford, Michael. (2003a). Interest and Prices: Foundations of a Theory of Monetary Policy. Princeton University Press.

—, (2003b). "Optimal interest rate smoothing.", Review of Economic Studies, 70, $861-886$.

Wyplosz, C. (2005): "Fiscal Policy: Institutions versus Rules", NIESR, No 191. 